\title{
Adverse outcome pathway-driven analysis of liver steatosis in vitro: a case study with cyproconazole
}

\author{
Claudia Luckert ${ }^{\dagger}$, Albert Braeuning ${ }^{\dagger,},{ }^{\star}$, Georges de Sousa ${ }^{\S}$, Sigrid Durinck\|, Efrosini S. \\ Katsanou $^{\perp}$, Parthena Konstantinidou ${ }^{\perp}$, Kyriaki Machera ${ }^{\perp}$, Emanuela S. Milani ${ }^{\bullet}$, Ad A.C.M. \\ Peijnenburg $^{\ddagger}$, Roger Rahmani ${ }^{\S}$, Andreja Rajkovic $\|$, Deborah Rijkers ${ }^{\ddagger}$, Anastasia Spyropoulou ${ }^{\perp}$, \\ Marianna Stamou ${ }^{\#, \bullet}$, Geert Stoopen ${ }^{\ddagger}$, Shana Sturla*, Bernd Wollscheid ${ }^{\#, \bullet}$, Nathalie Zucchini- \\ Pascal $^{\S}$, Alfonso Lampen ${ }^{\dagger}$ \\ ${ }^{\dagger}$ German Federal Institute for Risk Assessment, Department Food Safety, Berlin, Germany \\ ${ }^{\ddagger}$ RIKILT Wageningen University \& Research, Wageningen, The Netherlands \\ ${ }^{\S}$ French National Institute for Agricultural Research, INRA Unit 1331, TOXALIM, France

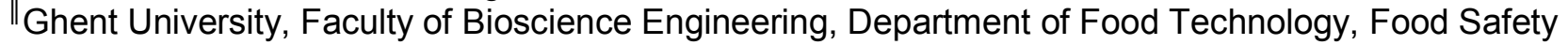 \\ and Health, Ghent, Belgium \\ ${ }^{\perp}$ Benaki Phytopathological Institute, Athens, Greece \\ \#ETH Zurich, Department of Health Sciences and Technology, Zurich, Switzerland \\ •ETH Zurich, BioMedical Proteomics Platform \& Institute of Molecular Systems Biology, Zurich, \\ Switzerland
}

${ }^{*}$ Corresponding author:

Albert Braeuning

German Federal Institute for Risk Assessment

Dept. Food Safety

Max-Dohrn-Str. 8-10

10589 Berlin

Germany

Phone +49-(0)30-18412-3758

Fax +49-(0)30-18412-63758

e-mail: Albert.Braeuning@bfr.bund.de 
Table of Contents Graphic

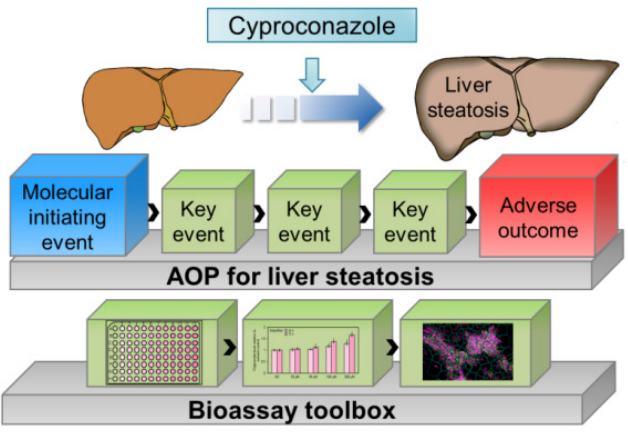




\section{Abstract}

Adverse outcome pathways (AOPs) describe causal relationships between molecular perturbation and adverse cellular effects, and are being increasingly adopted for linking in vitro mechanistic toxicology to in vivo data from regulatory toxicity studies. In this work, a case study was performed by developing a bioassay toolbox to assess key events in the recently proposed AOP for chemically induced liver steatosis. The toolbox is comprised of in vitro assays to measure nuclear receptor activation, gene and protein expression, lipid accumulation, mitochondrial respiration, and formation of fatty liver cells. Assay evaluation was performed in human HepaRG hepatocarcinoma cells exposed to the model compound cyproconazole, a fungicide inducing steatosis in rodents. Cyproconazole dose-dependently activated RARa and PXR, two molecular initiating events in the steatosis AOP. Moreover, cyproconazole provoked a disruption of mitochondrial functions and induced triglyceride accumulation and the formation of fatty liver cells as described in the AOP. Gene and protein expression analysis, however, showed expression changes different from those proposed in the AOP, thus suggesting that the current version of the AOP might not fully reflect the complex mechanisms linking nuclear receptor activation and liver steatosis. Our study shows that cyproconazole induces steatosis in human liver cells in vitro and demonstrates the utility of systems-based approaches in the mechanistic assessment of molecular and cellular key events in an AOP. AOP-driven in vitro testing as demonstrated can further improve existing AOPs, provide insight regarding molecular mechanisms of toxicity, and inform predictive risk assessment. 


\section{Introduction}

An important goal in the development of mechanism-based testing strategies for potential toxicants is to explore the utility of in silico and in vitro tools as parts of a refined risk assessment strategy. The concept of adverse outcome pathways (AOPs) has been introduced to link in vitro data to phenomenological effects observed in in vivo studies. AOPs are a conceptual framework to portray mechanistic toxicological knowledge about how chemicals lead to an adverse outcome. It directly links a molecular initiating event along a causal chain of molecular and cellular key events to an adverse outcome, which is relevant to risk assessment at a level of biological organization ${ }^{1,2}$. The concept of AOPs has gained attention in regulatory toxicology to facilitate the inclusion of mechanistic toxicological evidence into risk assessment in a formalized manner ${ }^{3}$. Knowledge of the molecular effects underlying the adverse outcome observed in in vivo studies is essential for establishing AOPs. However, measurement of these molecular events along an AOP is not included in current protocols for regulatory in vivo studies and moreover, for many of the events, in vivo or ex vivo analysis may be difficult or impossible. In contrast, in vitro analyses of individual molecular events appear as a viable strategy in order to determine changes along the AOP induced by a chemical of interest. This might be included in future toxicological testing strategies not only for individual compounds, but also for mixtures, a strategy which is, for example, pursued within the European project "European Test and Risk Assessment Strategies for Mixtures" (EuroMix; www.euromixproject.eu).

AOPs under development, under review or already accepted can be found at www.aopwiki.org. Amongst these, AOPs for drug-induced liver injury such as cholestasis, liver fibrosis and liver steatosis have recently been proposed ${ }^{4}$. In order to use this liver steatosis AOP as a basis of mechanism-based testing strategies for chemicals of concern, it would be advantageous to establish an in vitro assay toolbox that can be used to link in vitro data to phenomenological effects observed in in vivo studies. As a step toward this goal, it is necessary to understand how the different molecular initiating events and key events in the AOP for liver steatosis can be recapitulated in vitro.

Liver steatosis is a characteristic of fatty liver disease ${ }^{5}$. Non-alcoholic fatty liver disease in particular has gained growing attention due to an increasing prevalence over the last 20 years and is assumed to be the most common cause of chronic liver disease in the USA ${ }^{6}$. Liver steatosis can be caused by a wide variety of factors such as obesity, insulin resistance and exposure to alcohol and certain drugs ${ }^{7}$. It is marked by an increase in intracytoplasmic triglycerides in the liver ${ }^{8}$. Histologically, it can be divided into macrovacuolar steatosis characterized by large vacuoles leading to peripheral displacement and distortion of the nucleus, and microvacuolar steatosis consisting of numerous, smaller vacuoles without displacement of the nucleus. Severe liver failure and hypoglycemia can occur and, moreover, steatosis can progress into steatohepatitis which is associated with necroinflammation, fibrosis, cirrhosis and hepatocellular cancer ${ }^{5,9}$. 
Chemically induced steatosis is characterized by impaired synthesis and elimination of triglycerides. The interaction of chemicals with different nuclear receptors was proposed as the main molecular initiating event in the AOP for liver steatosis (Figure 1). LXR is a prominent transcriptional regulator of numerous genes involved in cholesterol and lipid metabolism and its activation was first included in the AOP $4,10,11$. LXR can stimulate the central key event of triglyceride accumulation in two ways: enhancing de novo fatty acid synthesis or upregulating fatty acid translocase (CD36) leading to an increased hepatic fatty acid influx from peripheral tissue ${ }^{4}$. De novo fatty acid synthesis enhancement is thought to occur by inducing transcriptional expression of MLX-interacting protein like (MLXIPL; also known as carbohydrate response element binding protein (CHREBP)), sterol regulatory element binding transcription factor 1 (SREBF1), fatty acid synthase (FASN), as well as stearoyl-CoA desaturase (SCD). The AOP for liver steatosis was recently extended to an AOP network by integrating additional nuclear receptors whose activation or antagonistic activity were proposed to serve as molecular initiating events independent of LXR activation ${ }^{12}$.

The aryl hydrocarbon receptor (AHR), the constitutive androstane receptor (CAR), the farnesoid $X$ receptor (FXR), the glucocorticoid receptor $(G R)$, the peroxisome proliferator-activated receptors (PPAR) $\alpha$ and $\gamma$, the pregnane $X$ receptor (PXR), and the retinoic acid receptor (RAR) all trigger hepatic steatosis upon ligand binding and are included in the AOP network for liver steatosis. Except for PPARa and RAR, activation of these receptors is proposed to induce hepatic triglyceride accumulation by sharing one or both of the mechanistic pathways described for LXR. In contrast, antagonistic binding to PPARa leads to the downregulation of acyl-CoA oxidase 1 (ACOX1) which is linked to an inhibition of microsomal $\beta$-oxidation and thus stimulates triglyceride accumulation. RAR activation is also associated with an increase in hepatic triglycerides without any further information on the underlying molecular mechanisms. In hepatic steatosis, accumulation of macrovacuolar lipid droplets is concomitant with cytoplasm displacement, distortion of the nucleus, mitochondrial disruption and endoplasmic reticulum stress at detected at the organelle level. In vivo, this condition can be classified as hepatic steatosis if the triglyceride content accounts for $5 \%$ to $10 \%$ of total liver weight ${ }^{4,12}$. A slightly different approach of building an AOP network for hepatic steatosis has been followed by Angrish et al. 2016 and $2017^{13,14}$ : here, the AOP was subdivided into four apical key events, namely alterations in fatty acid influx, efflux, degradation, and synthesis. Despite the substantive recent data contributing to building the liver steatosis AOP network, to our knowledge there has been no in vitro test battery established for recapitulating the diverse relevant molecular initiating and key events. Previous studies by Angrish et al. ${ }^{14}$ and Tolosa et al. ${ }^{15}$ focus on later apical key events, whereas molecular initiating events and details of the thereof-dependent mRNA and protein expression alterations have not been integrated in a comparable testing battery yet.

The goal of this study was to combine several in vitro assays to measure different key events in the AOP network for liver steatosis, based on the wider spread steatosis AOP concept by Vinken ${ }^{4}$, and 
Mellor et al. ${ }^{12}$, and to evaluate how perturbation of these key events is linked to the apical adverse outcome (steatosis). Thus, the in vitro assays assessed nuclear receptor activation, gene and protein expression, triglyceride accumulation, mitochondrial respiration as well as the occurrence of fatty liver cells (Figure 1). The assays were conducted using human HepaRG cells, a human hepatocellular carcinoma cell line which is readily available, showing unlimited growth, phenotypic stability during culture and stability in enzymatic activities and as such overcomes severe limitations of primary human hepatocytes. HepaRG cells retain a high expression of major cytochrome P450 enzymes, phase II enzymes and nuclear receptors and retain a functional metabolic competence which is comparable to primary human hepatocytes and exceeds that of other commonly used human hepatic cell lines like HepG2 ${ }^{16-20}$. Furthermore, HepaRG cells have been successfully employed as a cell model to assess hepatic steatosis ${ }^{14,15,21,22}$. We selected cyproconazole as a test compound in the present study (Figure 2). This triazole fungicide increases liver weight, induces hepatocellular hypertrophy and fat vacuolization, and leads to an accumulation of hepatocellular lipids in rodents, and has thus been linked to the development of steatosis ${ }^{23-26}$. Steatotic effects of cyproconazole are thought to be mediated via the lipid metabolism-associated nuclear receptors CAR and PXR which have been described as molecular initiating events in the steatosis AOP ${ }^{24-28}$. The results of this study demonstrate how AOP-driven in vitro testing could help improve existing AOPs, elucidate molecular mechanisms of toxicity in human cell systems in vitro, and assist predictive risk assessment.

\section{Experimental procedures}

\subsection{Chemicals}

Cyproconazole was obtained from Syngenta (Basel, Switzerland) as technical grade (batch \# CHF1E00042; purity 96.8\%) and a 200 mM stock solution was prepared in dimethyl sulfoxide (DMSO).

\subsection{Plasmids}

Plasmids pGAL4/DBD-CAR/LBD(+3aa) ${ }^{29}$, pCR3-hCAR1+A ${ }^{30}$ and pGAL4-PPARa-LBD, pGAL4PPARY-LBD and pGAL4-PPARס-LBD ${ }^{31}$ were kindly provided by Dr. Y. Kanno (Toho University, Funabashi, Japan), Dr. Hongbing Wang (University of Maryland, Baltimore, USA) and Dr. S. Kliewer (University of Texas Southwestern Medical Center, Dallas, USA). Plasmids pcDNA3-Rluc, pGAL4(UAS)5-TK-Luc, pGAL4-PXR-LBD and pSG5-hPXR have been described previously ${ }^{32}$. Plasmid pGREluc was obtained from Takara Bio Europe (Saint-Germain-en-Laye, France). Plasmids p3xDREC ${ }^{33}$, pGL3-CYP2B6-wt-luc ${ }^{34}$, pSG5-hVDR ${ }^{35}$, as well as pCMX-GAL4-hRAR $\alpha$ and pCMX-GAL4-hRXRa ${ }^{36}$ have also been described. The plasmid pGAL4-LXRa-LBD was derived from pGAL4-hPPARY-LBD by excising the ligand-binding domain (LBD) of hPPARy using restriction enzymes Acc65I and BamHI and inserting the LBD of LXRa, which was amplified from human cDNA using the primers 5'- AGC TGG 
TAC CCG GGA GGA GTG TGT CCT GTC-3' (forward, Acc65l site underlined) and 5'- AGC TGG ATC CTC ATT CGT GCA CAT CCC AGA TC-3' (reverse, BamHI site underlined), into the cleaved vector. Plasmid pGAL4-FXR-LBD was constructed similarly using the primers 5'-AGC AGG TAC CTT AAC TGA AAT TCA GTG TA-3' (forward, Acc65l site underlined) and 5'-AGC TGG ATC CTC ACT GCA CGT CCC AGA TTT CAC AGA-3' (reverse, BamHI site underlined) to amplify the LBD of FXR from human cDNA.

\subsection{HepaRG cell culture and exposure to test compounds}

Undifferentiated HepaRG cells were purchased from Biopredic International (Saint Grégoire, France). Cells were seeded at a density of approximately 25,000 cells $/ \mathrm{cm}^{2}$ and cultivated in William's Medium E with $2 \mathrm{mM}$ glutamine (PAN-Biotech, Aidenbach, Germany) supplemented with $10 \%(\mathrm{v} / \mathrm{v})$ fetal bovine serum (FBS; FBS Good Forte EU approved, PAN-Biotech, Aidenbach, Germany or HyClone FetalClone II, Thermo Fisher Scientific, Waltham, USA), $100 \mathrm{U} / \mathrm{ml}$ penicillin and $100 \mu \mathrm{g} / \mathrm{ml}$ streptomycin (Capricorn Scientific, Ebsdorfergrund, Germany) and $5 \times 10^{-5} \mathrm{M}$ hydrocortisone hemisuccinate (Sigma-Aldrich, St. Louis, USA) at $37^{\circ} \mathrm{C}$ in a humidified atmosphere containing $5 \%$ $\mathrm{CO}_{2}$. For differentiation, cells were maintained in culture medium for 14 days after seeding, followed by another 14 days of cultivation in the above-mentioned culture medium containing additionally $1.7 \%$ DMSO. For treatment with cyproconazole, differentiated HepaRG cells were first adapted to treatment medium (culture medium containing only $2 \%$ FBS and $0.5 \%$ DMSO) for $48 \mathrm{~h}$. After adaptation cells were exposed to cyproconazole in treatment medium for $24 \mathrm{~h}$ or $72 \mathrm{~h}$ with a final DMSO concentration of $0.5 \%$.

\subsection{Cultivation of HEK-293 and HepG2 cells}

The human hepatocellular carcinoma cell line HepG2 and the human embryonic kidney cell line HEK293 were purchased from the European Collection of Cell Cultures (ECACC, Salisbury, UK). The cells were cultured in Dulbecco's modified Eagle's medium (DMEM, PAN-Biotech, Aidenbach, Germany) supplemented with $10 \%$ (v/v) fetal calf serum (PAN-Biotech, Aidenbach, Germany), $100 \mathrm{U} / \mathrm{ml}$ penicillin and $100 \mu \mathrm{g} / \mathrm{ml}$ streptomycin (Capricorn Scientific, Ebsdorfergrund, Germany) at $37^{\circ} \mathrm{C}$ in a humidified atmosphere containing $5 \% \mathrm{CO}_{2}$. Cells were passaged at a confluence of about $80-90 \%$ and seeded at a density of 60,000 cells $/ \mathrm{cm}^{2}$.

\subsection{Cell viability analysis}

Cytotoxic effects of cyproconazole were analyzed using the cell proliferation reagent WST-1 (SigmaAldrich, St. Louis, USA). HepG2 and HEK-293 cells were seeded in 96-well plates and incubated for 24 $\mathrm{h}$ with different concentrations of cyproconazole dissolved in culture medium with a final solvent concentration of $0.5 \%$ DMSO. HepaRG cells were seeded in 96-well plates and after 28 days in culture cells were treated with increasing concentrations of cyproconazole for $24 \mathrm{~h}$ or $72 \mathrm{~h}$. Triton X-100 
( $0.01 \%)$ served as a positive control. One hour before the end of incubation $10 \mu \mathrm{l}$ WTS-1 reagent were added to each well containing $100 \mu \mathrm{l}$ medium and plates were returned to the incubator. At the end of the incubation period, absorbance was measured at $450 \mathrm{~nm}$ with a reference wavelength of $620 \mathrm{~nm}$ using the plate reader Infinite M200 Pro (Tecan group, Männedorf, Switzerland). Values of the reference wavelength were subtracted from absorbance values and data were corrected for background absorbance by subtracting the values from wells incubated without cells. Data were referred to solvent control which was set to $100 \%$. Dose response curve fitting (four parameter logistic curve) was performed with SigmaPlot 13.0 (Systat Software, Erkrath, Germany) and values for inhibitory concentration of $10 \%$ (IC10) were determined. At least two independent, biological replicates with five to six technical replicates per condition were performed.

\subsection{Reporter gene assays}

A panel of 14 reporter gene assays was used to analyze the activation of 12 nuclear receptors upon cyproconazole exposure of HepG2 and HEK-293 cells. Transactivation assays (CAR, FXR, LXRa, PPARa, PPARY, PPARס, PXR, RARa, RXRa) rely on fusion constructs between the GAL4 DNAbinding domain (DBD) and the ligand-binding domain (LBD) of a specific nuclear receptor. Transcription of the reporter gene firefly luciferase is controlled by the GAL4-specific upstream activation sequence (UAS) on a second plasmid. Agonistic binding of a test compound to the LBD of the nuclear receptor of interest leads to the activation of the fusion protein, which binds to the UAS and initiates transcription of the firefly luciferase gene.

Since the GAL4-dependent assay is only dependent on the components encoded by the plasmids and is independent of any endogenous factors provided by the host cell line, and due to an increased transfection efficiency of HEK-293 in comparison to HepG2 cells, the transactivation assays were performed in HEK-293 cells.

Reporter gene assays for AHR, GRE as well as CAR-CYP2B6, PXR-CYP2B6 and VDR-CYP2B6 are based on nuclear receptor-specific DNA response elements that directly regulate transcription of the reporter gene firefly luciferase. These assays were performed in HepG2 cells as they require the presence of certain endogenous factors provided by the host cell line and we observed no induction of reporter gene expression in HEK-293 cells (data not shown).

HepG2 and HEK-293 cells were seeded in 96-well plates and after $24 \mathrm{~h}$, cells were transiently transfected for 4-6 $\mathrm{h}$ with the appropriate plasmids using TransIT-LT1 (Mirus Bio, Madison, USA) according to the manufacturer instructions. A plasmid constitutively expressing the reporter gene Renilla luciferase was co-transfected as an internal control for normalization. Following transfection, cells were exposed for $24 \mathrm{~h}$ to $15 \mu \mathrm{M}, 30 \mu \mathrm{M}$ or $60 \mu \mathrm{M}$ cyproconazole in culture medium with $0.5 \%$ DMSO. For each reporter gene assay a specific positive control was included (supplement, Table S1). Cells were lysed with $50 \mu$ lysis buffer $(100 \mathrm{mM}$ potassium phosphate with $0.2 \%(\mathrm{v} / \mathrm{v})$ Triton X-100, pH 
7.8) on an orbital shaker, then centrifuged (5000 x g, $5 \mathrm{~min}$ ). Subsequently, $5 \mu$ l of supernatant were analyzed for firefly and Renilla luciferase activities in a dual luciferase assay as previously described (Hampf and Gossen, 2006) using a Mithras LB940 (Berthold Technologies, Bad Wildbad, Germany) or an Infinite M200 Pro (Tecan group, Männedorf, Switzerland) luminometer. Three to four independent, biological replicates were performed with four technical replicates per condition. Firefly luciferase activity was normalized to Renilla luciferase activity and expressed as relative activity referred to the positive control. Statistical analysis was performed with SigmaPlot 13.0 (Systat Software, Erkrath, Germany) using the non-parametric Kruskal-Wallis test followed by Dunn's test. Statistical significance was assumed at $p<0.05$. An overview of the specific conditions for each reporter gene assay (plasmid, plasmid amount, cell line, positive control) is provided as a supplement (Table S1).

\subsection{Analysis of mRNA expression levels}

HepaRG cells were differentiated in 12-well plates and treated with $25 \mu \mathrm{M}, 50 \mu \mathrm{M}, 100 \mu \mathrm{M}$ or $200 \mu \mathrm{M}$ cyproconazole or solvent control $(0.5 \% \mathrm{DMSO})$ for $24 \mathrm{~h}$ as described above. Cells were washed twice with ice-cold PBS and lysed with $350 \mu \mathrm{RLT}$ buffer (RNeasy Mini Kit, Qiagen, Hilden Germany). Total RNA was extracted according to the manufacturer protocol. The RNA was quantitated spectrophotometrically at $260 \mathrm{~nm}$ (A260) by using a nanophotometer P330 (Implen, München, Germany). An A260/280 ratio of $>1.8$ was considered an acceptable measure of RNA purity. RNA integrity was estimated by visual examination of two distinct rRNA bands (28S and 18S) on a denaturing $1 \%$ agarose gel stained with SYBR Gold. Only RNA samples with a clear and sharp $28 \mathrm{~S}$ rRNA band about twice as intense as that of 18S rRNA were used. For first-strand cDNA synthesis, 2 $\mu \mathrm{g}$ of total RNA were reverse-transcribed into cDNA in a total volume of $20 \mu \mathrm{l}$, using the SuperScript First-Strand Synthesis System for RT-PCR (Thermo Fisher Scientific, Waltham, USA) according to the manufacturer instructions using oligo dT primers for the reaction. TaqMan Gene expression assays (Thermo Fisher Scientific, Waltham, USA) were used to measure the expression of 69 genes linked to liver steatosis, nuclear receptor activation and hepatotoxicity (supplement, Table S2). TaqMan Gene Expression Assays consisted of a pair of unlabeled PCR primers and a TaqMan probe with FAM dye label on the 5' end and minor groove binder (MGB) as well as a nonfluorescent quencher (NFQ) on the 3 ' end. All genes were amplified by real-time PCR in the Step One Plus detection system with StepOnePlus Software v2.3 (Thermo Fisher Scientific, Waltham, USA). Each amplification reaction was carried out in a total volume of $20 \mu \mathrm{l}$ containing $10 \mu \mathrm{l}$ TaqMan gene expression master mix (Thermo Fisher Scientific, Waltham, USA), $1 \mu$ l TaqMan gene expression assays and $20 \mathrm{ng} \mathrm{cDNA}$. The reactions were cycled 40 times using the following parameters: $95^{\circ} \mathrm{C}$ for $15 \mathrm{~s}$ and $60{ }^{\circ} \mathrm{C}$ for $1 \mathrm{~min}$ during which the fluorescence data were collected. A non-template control was run with every set of primers. Expression levels of the target genes were normalized to the reference genes ACTB (actin beta: Hs01060665_g1), GAPDH (glyceraldehyde -3-phosphate dehydrogenase: Hs02758991_g1) and 
B2M (beta-2-microglobulin: Hs00187842_m1) which were found to be stably expressed throughout treatments. RNA from three independent, biological replicates was used. Each cDNA was analyzed at least in duplicate by real-time PCR. Relative gene expression was calculated using the $\triangle \triangle C T$ method 37. Statistical significance of differences in expression was assessed by the non-parametric KruskalWallis test followed by Dunn's test, using GraphPad Prism v.7 (GraphPad Software, La Jolla, USA). A $p$ value $<0.05$ was assumed statistically significant. The statistical calculation was based on $2^{-\triangle C t}$ values.

\subsection{Protein extraction and parallel reaction monitoring (PRM) analysis}

HepaRG cells were differentiated in $15 \mathrm{~cm}$ dishes and exposed to $25 \mu \mathrm{M}, 50 \mu \mathrm{M}, 100 \mu \mathrm{M}$ or $200 \mu \mathrm{M}$ cyproconazole or solvent control ( $0.5 \%$ DMSO) as described above. After $72 \mathrm{~h}$ cells were harvested by incubating with $2 \mathrm{mM}$ EDTA for 15 minutes at $37^{\circ} \mathrm{C}$. Harvested cells were centrifuged at $300 \times g$ for 3 min at $4{ }^{\circ} \mathrm{C}$, supernatants were removed and cell pellets were snap-frozen in liquid nitrogen and stored at $-80{ }^{\circ} \mathrm{C}$ until further analysis. Cells ( 3 independent, biological replicates per experimental condition) were lysed with $8 \mathrm{M}$ urea in ammonium bicarbonate, sonicated twice in a VialTweeter (Hielscher, Wanaque, USA) at $100 \%$ amplitude, 0.8 cycle, for 10 s and centrifuged at $20,000 \times g$ for 20 min to remove any remaining debris. Protein concentration in the extracts was determined by the bicinchoninic acid assay (BCA Protein Assay Kit, Thermo Fisher Scientific, Waltham, USA) and $100 \mu \mathrm{g}$ per sample were used for further protein extraction. RapiGest surfactant $(0.1 \%)$ was added to each sample and proteins were reduced with $5 \mathrm{mM}$ TCEP (Thermo Fisher Scientific, Waltham, USA) at 37 ${ }^{\circ} \mathrm{C}$ for $30 \mathrm{~min}$ and then alkylated with $10 \mathrm{mM}$ iodoacetamide (Fluka, Buchs, Switzerland) in the dark at $37{ }^{\circ} \mathrm{C}$ for $30 \mathrm{~min}$. Samples were diluted with $100 \mathrm{mM}$ ammonium bicarbonate to $4 \mathrm{M}$ urea and Lys $\mathrm{C}$ (Wako, Neuss, Germany) was added at a 1:100 enzyme to protein ratio and incubated for $3 \mathrm{~h}$ at $37^{\circ} \mathrm{C}$. Samples were then diluted to $1.5 \mathrm{M}$ urea using $100 \mathrm{mM}$ ammonium bicarbonate before adding trypsin (Sigma-Aldrich, St. Louis, USA) at a 1:100 trypsin to protein ratio. Tryptic digestion was carried out overnight at $37{ }^{\circ} \mathrm{C}$. The peptide mixtures were acidified to $\mathrm{pH} 3$ by the addition of formic acid to inactivate trypsin and the precipitated RapiGest was removed by centrifugation (13,000 x $g$ for $10 \mathrm{~min}$ ). The peptide mixture was further subjected to C18 purification using Sep-Pak Vac 1cc $(50 \mathrm{mg})$ tC18 Cartridges (Waters, Eschborn, Germany) according to the manufacturer instructions.

For the parallel reaction monitoring (PRM) LC-MS/MS method ${ }^{38}$ proteins were selected corresponding to the steatosis-relevant gene transcripts examined at the mRNA expression level. PRM assays were generated in Skyline ${ }^{39}$ (version 3.5.0.9319) using a spectral library generated in-house by discoverybased LC-MS/MS analysis from the same samples and the background proteome from UniProtKB/Swiss-Prot (June 2014) specific to Homo Sapiens. At least 2 quantotypic peptides were selected for each protein and tested in PRM mode to select the most suitable peptides. Retention time windows for the PRM assays were defined by analyzing a pooled sample (aliquot of all conditions and 
biological replicates pooled together) in PRM mode. The final isolation list consisted of 104 peptides derived from 41 proteins (including iRT peptides (Biognosys, Schlieren, Switzerland) for retention time normalization ${ }^{40}$ ), which were detected in scheduled PRM mode. Subsequent PRM analysis was carried out on individual biological replicates on an Orbitrap Fusion mass spectrometer (Thermo Fisher Scientific, Waltham, USA). Peptide samples were separated by a 2 h-gradient reversed-phase chromatography on a high pressure liquid chromatography (HPLC) column (75 $\mu \mathrm{m}$ inner diameter, New Objective, Woburn, USA) which was packed in-house with a $15 \mathrm{~cm}$ stationary phase (ReproSil-Pur C18-AQ,1.9 $\mu \mathrm{m}$ ) and connected to a nano-flow HPLC combined with an autosampler (EASY-nLC II, Proxeon, Odense, Denmark). Mass spectra were acquired in a data-dependent acquisition (DDA) manner, with an automatic switch between MS and MS/MS scans. High resolution MS scans were acquired in the Orbitrap (resolution 60,000, $50 \mathrm{~s}$ injection time) to monitor peptide ions across the mass range of $350-1400 \mathrm{~m} / \mathrm{z}$, followed by higher energy collision dissociation (HCD) MS/MS scans of the targeted peptides in the Orbitrap (resolution 15,000, 34 injection time, isolation window $1.4 \mathrm{~m} / \mathrm{z}$ ). PRM data were analyzed in Skyline. Peak boundaries were individually inspected and manually set if necessary. Peaks with the lowest mass error value and best match to the library, relative fragment-ion intensities and peak shape similarity were selected for further quantitative analysis. Samples with more than 5 min retention time shift were excluded from further analysis (one of three biological replicates in the $0 \mu \mathrm{M}$ condition and one of three biological replicates in the $200 \mu \mathrm{M}$ condition were excluded). In addition, only peaks appearing in all samples and conditions with at least 3 transitions per peptide with no obvious interference were considered. A total of 62 peptides derived from 34 proteins were considered for quantitative analysis (supplement, Table S3). Raw peak areas were exported from Skyline and further analyzed. Peptide intensities were summarized at the protein level by averaging. Quantification was performed by comparing to the untreated control samples. Abundance changes were reported as log2 fold changes \pm SEM using Student's t-test under the assumptions of normal distribution and equal variance.

\subsection{AdipoRed assay}

Levels of triglycerides were measured using the AdipoRed assay essentially according to the instructions of the supplier (Lonza, Basel, Switzerland). After $24 \mathrm{~h}$ or $72 \mathrm{~h}$ treatment of differentiated HepaRG cells in 96-well micro titer plates with $25 \mu \mathrm{M}, 50 \mu \mathrm{M}, 100 \mu \mathrm{M}$ or $200 \mu \mathrm{M}$ cyproconazole or solvent control $(0.5 \%$ DMSO), the cell monolayer was rinsed with $200 \mu$ DPBS (Fisher Scientific, Hampton, USA) and subsequently incubated for $10 \mathrm{~min}$ at room temperature with $200 \mu \mathrm{l}$ AdipoRedDPBS solution. The latter solution was prepared by adding $25 \mu \mathrm{l}$ AdipoRed to $1 \mathrm{ml}$ DPBS. Subsequently, fluorescence was measured using a 485/20 nm excitation and 590/35 emission filter set on the Synergy HT Microplate Reader (BioTek, Winooski, VT). Relative triglyceride levels were referred to solvent control and statistically analyzed with SigmaPlot 13.0 (Systat Software, Erkrath, Germany) 
using the non-parametric Kruskal-Wallis test followed by Dunn's test. Statistical significance was assumed at $p<0.05$. Four independent, biological replicates with three technical replicates per condition were performed.

\subsection{Triglyceride extraction and analysis by GC-FID (gas chromatography with flame-ionization detection)}

Upon treatment of differentiated HepaRG cells in 12-well culture plates with $25 \mu \mathrm{M}, 50 \mu \mathrm{M}, 100 \mu \mathrm{M}$ or $200 \mu \mathrm{M}$ cyproconazole or solvent control (0.5\% DMSO), the monolayer was rinsed three times with 1 $\mathrm{ml}$ DPBS/well. Cells were harvested in $300 \mu \mathrm{LPBS}$ with a rubber policeman and transferred to a 1.5 $\mathrm{ml}$ Eppendorf Protein LoBind micro centrifuge tube (Fisher Scientific, Hampton, USA). The samples were stored at $-80{ }^{\circ} \mathrm{C}$ until extraction. Extraction of triglycerides was performed under an $\mathrm{N}_{2}$ atmosphere according to a method described by Hutchins et al. ${ }^{41}$ using isooctane:ethylacetate $(75: 25)$. After thawing, the samples were transferred to $10 \mathrm{ml}$ glass tubes and sonicated for one minute in icecold water. A mixture of isooctane and ethylacetate $(75: 25,5 \mathrm{~mL})$ with $10 \mu \mathrm{l} 0.5 \mathrm{mg} / \mathrm{ml}$ tritridecanoin (Nu-Chek Prep Inc., Elysian, USA) was added to the samples, followed by vortex-mixing (30 s), sonication (60 s), vortex-mixing (30 s) and incubation head over head (15 min). $\mathrm{NaCl}(1 \mathrm{ml}, 0.9 \%)$ was added and the samples were vortex-mixed for $60 \mathrm{~s}$ and centrifuged for $10 \mathrm{~min}$ at $1000 \mathrm{xg}$ to separate the two phases. A total of $4.2 \mathrm{ml}$ of the organic (upper) phase was collected with a 1-ml glass Hamilton syringe. The polar phase was extracted again by adding $2 \mathrm{ml}$ isooctane:ethylacetate 75:25 followed by vortex-mixing, centrifugation and collection of the organic phase. The two organic phases were combined, dried under $\mathrm{N}_{2}$ gas at $30-37^{\circ} \mathrm{C}$, redissolved in $100 \mu \mathrm{l}$ isooctane and transferred to a GC vial. The samples were analyzed on a Trace GC Ultra GC-FID system (Thermo Fisher Scientific, Waltham, USA). A sample volume of $2 \mu \mathrm{l}$ was injected on a $5 \mathrm{~m} \times 0.53 \mathrm{~mm}, 0.17 \mu \mathrm{m}$ Sim Dist Ulti Metal column (CP7532, Agilent Technologies, Santa Clara, USA) and eluted at a $N_{2}$ gas flow of $45.5 \mathrm{ml} / \mathrm{min}$. The temperature program was as follows: $1 \mathrm{~min} 90^{\circ} \mathrm{C}, 20^{\circ} \mathrm{C} / \mathrm{min}$ ramp to $230^{\circ} \mathrm{C}, 5^{\circ} \mathrm{C} / \mathrm{min}$ ramp to $315^{\circ} \mathrm{C}$, $10 \mathrm{~min}$ hold at $315^{\circ} \mathrm{C}$. The detector temperature was $350^{\circ} \mathrm{C}$. A triglyceride standard mixture (palm kernel triglycerides, BCR 632 A, Sigma-Aldrich, St. Louis, USA) was included in each sequence to calibrate the retention times of the triglycerides. Triglycerides were quantified by determining the AUC and the relative triglyceride level was calculated by dividing the AUC of the test compounds by the AUC of the solvent control. Two independent, biological replicates with three technical replicates per condition were performed. Statistical analysis was performed with SigmaPlot 13.0 (Systat Software, Erkrath, Germany) using the non-parametric Kruskal-Wallis test followed by Dunn's test. Statistical significance was assumed at $p<0.05$.

\subsection{Mitochondrial respiration}

Mitochondrial respiration as an indicator of cellular metabolism and fitness in response to the exposure of HepaRG cells to cyproconazole was determined by extracellular flux analysis using an Agilent 
Seahorse XF24 Analyzer (Agilent Seahorse Bioscience, Santa Clara, CA USA). Extracellular flux analysis comprises measurement of oxygen consumption rate (OCR) in treated and control cells. Measurements of OCR can decipher key parameters of mitochondrial respiration when different aspects of electron transport chain are shut down by respiration modulators. For this purpose oligomycin (2 $\mu \mathrm{M})$ was used to block ATP synthase, carbonyl-cyanide-4-(trifluoromethoxy) phenyhydrazone (FCCP, $1 \mu \mathrm{M}$ ) was used to make the inner mitochondrial membrane permeable for protons and allow maximum electron flux through the electron transport chain, and a mix of rotenone $(0.5 \mu \mathrm{M})$ and antimycin $\mathrm{A}(0.5 \mu \mathrm{M})$ were used together to inhibit complexes I and III, respectively. Through use of mitochondrial inhibitors, four key mitochondrial respiration parameters were measured: basal, ATP production-linked, maximal, and proton leak-linked OCR ${ }^{42}$. Based on these data, spare respiratory capacity and non-mitochondrial respiration also were calculated.

To meet stringent prerequisites of the extracellular flux analysis for highly optimized and controlled seeding density of the cells ${ }^{43}$ a minor adaptation was made to the methods described under section 2.3 (HepaRG cell culture and exposure to test compounds). Prior to seeding for the treatment, differentiated HepaRG cells were washed two times with pre-warmed $\left(37^{\circ} \mathrm{C}\right)$ PBS and were released from $75 \mathrm{~cm}^{2}$ cell culture flasks using trypsin-EDTA to obtain single cell suspensions. HepaRG cells then were seeded in a Seahorse 24-well XF cell culture microplate with 30,000 cells in $200 \mu$ treatment medium per well. Plates were incubated for $24 \mathrm{~h}$ at $37{ }^{\circ} \mathrm{C}$ with $5 \% \mathrm{CO}_{2}$ to allow for cell adherence. On the following day, XF assay media with or without cyproconazole was prepared and adherent cells were treated by adding $200 \mu \mathrm{l}$ of this medium to each well exposing cells to $0 \mu \mathrm{M}, 25 \mu \mathrm{M}, 50 \mu \mathrm{M}, 100$ $\mu \mathrm{M}$ or $200 \mu \mathrm{M}$ cyproconazole. The plates were incubated at $37{ }^{\circ} \mathrm{C}, 5 \% \mathrm{CO}_{2}$ for $24 \mathrm{~h}$ or $72 \mathrm{~h}$.

The day prior to the Seahorse XF run the Sensor cartridges were hydrated by adding $1 \mathrm{ml}$ of XF Calibrant to each well of the Seahorse Utility Plate. The hydrated cartridges were wrapped in sterile Stomacher bags and incubated in a non- $\mathrm{CO}_{2}$ incubator at $37^{\circ} \mathrm{C}$ for $24 \mathrm{~h}$. The Seahorse instrument was started and kept on until the day of analysis to assure stable temperature of $37^{\circ} \mathrm{C}$ in the microtiter heating block.

On the day of analysis plates were taken from the incubator, and cells were visually checked for their morphology, seeding uniformity, and adherence. Each plate was washed three times with $100 \mathrm{ml}$ of pre-warmed $\left(37{ }^{\circ} \mathrm{C}\right)$ filter sterilized $\mathrm{XF}$ assay medium (non-buffered DMEM base medium supplemented with $10 \mathrm{mM}$ glucose, $1 \mathrm{mM}$ sodium pyruvate and $2 \mathrm{mM} \mathrm{L-glutamine;} \mathrm{adjusted} \mathrm{to} \mathrm{pH} 7.4$ ). The washing medium was removed from each well and cells were rinsed two times with $1 \mathrm{ml}$ of prewarmed $\left(37^{\circ} \mathrm{C}\right)$ assay medium. Finally, $525 \mu \mathrm{l}$ of the assay medium was added to each well and cells were observed under the microscope to ensure that cells were not washed away. The plates were placed in a $37{ }^{\circ} \mathrm{C}$ non- $\mathrm{CO}_{2}$ incubator for $1 \mathrm{~h}$ prior to the assay. During this time, solutions of mitochondrial modulators oligomycin, FCCP and rotenone/antimycin A were prepared with pre-made XF assay media (Seahorse Bioscience) warmed to $37^{\circ} \mathrm{C}$. These were loaded (75 $\left.\mu \mathrm{l}\right)$ into designated 
injection ports of sensor cartridges. Subsequently, the loaded XF sensor cartridge with the XF utility plate was placed into the XF24 Analyzer and calibrated. After calibration, the XF utility plate containing calibration fluid was replaced with the plate containing the cells. The software of the XF24 instrument was programmed to first perform 3 basal OCR measurements, followed by the sequential addition of oligomycin, FCCP, and rotenone/antimycin A. Measurement cycles performed after each addition consisted of $3 \mathrm{~min}$ of mixing the cell suspension, $2 \mathrm{~min}$ of waiting, and $3 \mathrm{~min}$ of OCR measurement. Results were presented as values of OCR corresponding to basal respiration, ATP production-linked respiration, maximal respiration, proton leak-linked respiration, spare respiratory capacity and nonmitochondrial respiration. The statistical significance of values reflecting the impact of cyproconazole on measured respiration parameters in three independent, biological replicates with three technical replicates was tested by the non-parametric Kruskal-Wallis test against negative control values (assay medium with $0.5 \% \mathrm{DMSO}$ ) with $p<0.05$ indicating statistically significant differences.

\subsection{Nile Red staining and neutral lipid droplet analysis by high content cell imaging}

HepaRG cells were differentiated in 96-well plates (black plate, clear bottom, Corning Life Sciences, Amsterdam, Netherlands) and treated in triplicates with $25 \mu \mathrm{M}, 50 \mu \mathrm{M}, 100 \mu \mathrm{M}$ or $200 \mu \mathrm{M}$ cyproconazole, solvent control ( $0.5 \% \mathrm{DMSO})$ or a positive control (30 $\mu \mathrm{M}$ cyclosporin A) as described above within three independent experiments. After $24 \mathrm{~h}$ and $72 \mathrm{~h}$ of exposure, cells were fixed in $4 \%$ $(\mathrm{w} / \mathrm{v})$ paraformaldehyde in PBS for $30 \mathrm{~min}$. Cells were then washed 3 times with PBS and stained overnight (at $4{ }^{\circ} \mathrm{C}$ ) with $100 \mu \mathrm{l}$ of $0.9 \mu \mathrm{M}$ Nile Red (Sigma-Aldrich, St. Louis, USA) solution in PBS ${ }^{44,45}$. Two hours before reading $50 \mu \mathrm{l}$ of $0.3 \mu \mathrm{g} / \mathrm{ml}$ DAPI in PBS were added to each well (incubation at ambient temperature in the dark). The multi-well plates were scanned (9 images) with an Arrayscan XTI using a 20x NA 0.4 objective (Plan NeoFluar, Zeiss, Oberkochen, Germany). The Photometrics X1 CCD camera was set with a binning 2 (14 bits dynamic range, $4 \times 106$ pixels with a size of $4.54 \mu \mathrm{m}$ ). Identification of the nuclei was done by tracking DAPI with an XF100-386-23 filter set and used to focus the instrument. Identification of neutral lipid spot was done by tracking Nile Red green emission with an XF 100_485_20 filter set. The Spot Detector V3 Bioapplication analysis algorithm (software V.6.5) identifies nuclei upon fluorescent intensity and size. The nuclear mask was dilated to define the cytoplasmic region. The following parameters were measured at the cell level. For the nuclei: area as well as total and average intensity for each cell; for the neutral lipid spot: spot number, spot area and spot intensity as well as total fluorescence of spot intensity within each cell.

To analyze the quantitative data for neutral lipid droplet accumulation obtained after the image analysis, a workflow was built in Statistica v13.2 (Tibco, Palo Alto, USA). Firstly, each independent plate was standardized in order to eliminate inter-experiment variation. The whole data set for neutral lipid spot total intensity within cells was submitted to a median MAD standardization in order to fix the values in the same order of magnitude (robust Z-score). Then the three independent experiments were 
grouped. Data were now normalized to the median of control cells (DMSO treated cells $=1$ ). Results are presented as box plot median \pm percentile $25 \%$ and $75 \%$ and non-outlier data. For statistical analysis the non-parametric Kruskal-Wallis test was performed. Statistical significance was assumed at $p<0.05$.

\subsection{3 $\mathrm{BMC}_{50}$ calculation}

Dose-response modeling and benchmark concentration (BMC) analysis were performed using the Rbased software package PROAST (version 64.14, RIVM, Bilthoven, Netherlands). Response data were provided as relative data normalized to the solvent control and submitted to PROAST as continuous, summary data containing mean, standard deviation and sample size in tab-delimited text files. Data were fitted to an exponential 3-parameter model (1) or to an exponential 4-parameter model (2):

$$
\begin{aligned}
& y=a\left[\exp \left(b x^{d}\right)\right] \\
& y=a\left[c-(c-1) \exp \left(-b x^{d}\right)\right]
\end{aligned}
$$

The model with the lowest Akaike information criterion (AIC) value was selected and the BMC and the corresponding two-sided 90\% BMC confidence interval given by BMCL (lower bound of the BMC confidence interval) and BMCU (upper bound of the BMC confidence interval) were calculated for a benchmark response of $50 \%\left(\mathrm{BMR}_{50}\right)$.

\section{Results}

The aim of this study was to compile an in vitro test battery covering the AOP for liver steatosis and to evaluate its capacity to detect the steatotic potential of a known steatotic chemical, namely the fungicide cyproconazole. Prior to analyses of functional molecular endpoints, cell viability of cyproconazole on the employed human cell lines HepaRG, HepG2 and HEK-293 was assessed to determine non-cytotoxic concentrations for further analyses. Cell viability of HepaRG cells was inhibited by $10 \%$ at concentrations $\left(\mathrm{IC}_{10}\right)$ of $449 \mu \mathrm{M}(24 \mathrm{~h})$ and $368 \mu \mathrm{M}(72 \mathrm{~h})$ cyproconazole (supplement, Figure S1A). In HepG2 and HEK-293 cells cyproconazole led to $10 \%$ inhibition of cell viability at $92 \mu \mathrm{M}$ (HEK-293) and $128 \mu \mathrm{M}$ (HepG2) after $24 \mathrm{~h}$ of exposure (supplement, Figure S1B). Maximal concentrations of $200 \mu \mathrm{M}$ cyproconazole for HepaRG cells and $90 \mu \mathrm{M}$ cyproconazole of HepG2 and HEK-293 cells were chosen for subsequent experiments in order to exclude unspecific cellular responses due to cytotoxic effects.

\subsection{Nuclear receptor activation}

Activation of different nuclear receptors is considered to constitute the molecular initiating event of liver steatosis $^{4,12}$, as delineated in the AOP for liver steatosis (Figure 1). Activation of a large set of nuclear 
receptors, namely AHR, CAR, FXR, GR, LXRa, PPAR, PPARy, PPARס, PXR, RAR, RXRa, and VDR by cyproconazole was monitored using luciferase-based reporter assays either in human HepG2 or HEK-293 cells, depending on the respective reporter gene assay. As listed in Figure 3A, most of the receptors were not affected by cyproconazole. Dose-dependent statistically significant induction of reporter activities was observed, however, for PXR (Figure 3B) activation of this receptor was consistently demonstrated in form of a GAL4 fusion construct-based assay aimed to monitor binding of a substance to the PXR ligand binding domain, as well as by a classic reporter assay utilizing the PXRresponsive human CYP2B6 promoter (Figure 3B). In addition, cyproconazole significantly activated luciferase reporter activity driven by the retinoid receptor RARa (Figure 3B). According to the AOP for liver steatosis, the antagonistic binding to PPARa also represents a molecular initiating event. However, no repression of basal activity of the reporter gene assay plasmid after exposure to cyproconazole could be observed, indicating that cyproconazole does not exhibit antagonistic PPAR binding properties (data not shown). Baseline levels of the PPARa reporter assay were high enough to be able to monitor potential down-regulation of the signal by a test compound.

\subsection{PCR-based gene expression analysis}

According to the AOP for liver steatosis and in line with previous knowledge regarding the consequences of nuclear receptor activation, changes in gene expression occur following binding of agonist ligands to their respective receptors. These gene expression changes are considered key events in the AOP for steatosis. A PCR array covering a selection of the most relevant genes involved in liver steatosis, nuclear receptor activation and hepatotoxicity was compiled and the effects of $200 \mu \mathrm{M}$ cyproconazole on target gene expression in human HepaRG hepatocarcinoma cells were analyzed as a screening approach to identify genes with changes in gene expression after cyproconazole exposure. The expression of genes showing deregulation by a $\mid$ fold change $\mid \geq 2$ in the PCR array (Figure 4A) was further examined in cells treated with increasing concentrations of cyproconazole in order to establish dose-response relationships in gene expression regulation by the fungicide (Figure 4B). As evident from the data in Figure 4B, a significant upregulation was observed for genes predominantly encoding enzymes involved in xenobiotic metabolism (CYP1A2, CYP2B6, CYP3A4, and CYP3A7). The strongest induction ( $>14$-fold) was observed for the PXR model target gene CYP3A4. A number of genes were downregulated upon cyproconazole treatment, including a minority of genes related to xenobiotic metabolism (CYP2E1, SULT1B1). Furthermore, downregulation was observed for additional genes, including CYP7A1, a crucial player in bile acid synthesis and the cell cycle regulator RGCC (Figure 4B). Regarding the genes listed in the AOP, only FASN and SCD were detected to be down or upregulated in the screening approach, respectively (Figure 4A). However, no significant gene expression changes of both genes could be confirmed in samples exposed to increasing 
cyproconazole concentrations (Figure 4A). Detailed data of the heat map in Figure 4B are provided in the supplement (Table S4).

\subsection{Protein abundance changes in HepaRG cells upon cyproconazole exposure}

Changes in the abundance of nuclear receptor targets and important players in steatosis were additionally monitored at the protein level using a mass spectrometric-based assay in HepaRG cell lysates following $72 \mathrm{~h}$ exposure to $25 \mu \mathrm{M}, 50 \mu \mathrm{M}, 100 \mu \mathrm{M}$ or $200 \mu \mathrm{M}$ cyproconazole. A set of parallel reaction monitoring (PRM) assays was designed for the identification and quantification of selected proteins corresponding to gene transcripts examined by gene array analysis (Figure 4). A total of 33 proteins were monitored using quantotypic peptides and their log2-fold changes relative to untreated cells were plotted as a heat map (Figure 5). The quantitative PRM data used for constructing the heat map in Figure 5 can be found in the supplement (Table S5) and the PRM assay coordinates are available upon request. Similar to the gene expression assays, the strongest protein abundance increase was observed for the PXR target CYP3A4 (Figure 5). CES2 was also significantly increased in abundance at all concentrations monitored. Regarding the genes listed in the AOP on steatosis, ACOX1 levels were significantly reduced in cyproconazole-treated HepaRG cells across all conditions monitored compared to untreated cells. FASN significantly decreased the two highest concentrations of cyproconazole. No significant changes in SCD protein abundance level were observed. MLXIPL, SREBF1 and CD36 were below the sensitivity level of the assays and could not be detected. Furthermore, protein abundance of CYP2A6, ALDH1A1, KHK, GPD1, MAPK3, MTTP, HAAO and UGT2B7 was significantly reduced at the highest cyproconazole concentration tested $(200 \mu \mathrm{M})$.

\subsection{Liver triglyceride accumulation}

In the steatosis AOP, liver cell triglyceride accumulation is a late key event that follows nuclear receptor activation and transcriptional changes (Figure 1). This parameter was monitored in human HepaRG cells after $24 \mathrm{~h}$ and $72 \mathrm{~h}$ of cyproconazole exposure using the fluorescence-based AdipoRed assay. As shown in Figure 6A, cyproconazole treatment led to a statistically significant and dose-dependent increase in cellular triglycerides, which was more pronounced after $72 \mathrm{~h}$ of exposure. This was confirmed by GC-FID analyses (Figure 6B, 6C), which demonstrated an even stronger increase in relative cellular triglyceride levels by cyproconazole, especially after $72 \mathrm{~h}$ for triglycerides with higher molecular weight (C54 and C56).

\subsection{Mitochondrial disruption}

Mitochondrial disruption is thought to be an organelle level effect causally linked to liver steatosis (Figure 1). Mitochondrial respiration was thus monitored in cyproconazole-treated human HepaRG cells using a Seahorse analyzer. Results of these assays demonstrate a decrease in basal and 
maximal respiration as well as in proton leak, spare respiratory capacity and ATP production after $72 \mathrm{~h}$ of $200 \mu \mathrm{M}$ cyproconazole exposure (Figure 7).

\subsection{Assessment of triglyceride accumulation at the single-cell level}

At the cellular level, the occurrence of fatty liver parenchyma cells is considered a hallmark of the development of steatosis. Following treatment of HepaRG cells with cyproconazole, a high content cell imaging approach was employed by staining triglycerides with the lipophilic dye nile red. Figure 8A visualizes fatty hepatocyte-like cells within the cultures of HepaRG cells consisting of a mixture of hepatocyte- and bile duct epithelium-like cells. The data presented in Figure 8B demonstrate that cyproconazole induced a statistically significant increase in lipid droplets in liver cells for both time points analyzed, i.e. $24 \mathrm{~h}$ and $72 \mathrm{~h}$ of incubation with the fungicide. These data are consistent with the observation of increased triglyceride levels in cyproconazole-treated HepaRG cells (Figure 6).

\subsection{Dose-response and temporal relationships between key events}

A principal characteristic of AOPs is the existence of dose-response relationships and temporal concordance between the different key events ${ }^{46,47}$. In order to compare the different key events analyzed in this study and the employed assays, we performed dose-response modeling for each data set and calculated the $\mathrm{BMC}_{50}$ value (i.e. the concentration at which a $50 \%$ change in the response occurs, relative to the background) (Table 1). Due to the complexity of gene and protein expression data we focused on the following key events: nuclear receptor activation, liver triglyceride accumulation, mitochondrial disruption and fatty liver cells. According to AOP principles different key events have to causally concur in their dose-response relationships. It implies that upstream (i.e. preceding) key events occur at lower concentrations than subsequent downstream events. Consequently, the incidence for an upstream event is higher than that of a downstream key event for the same concentration of a tested stressor. This concordance of dose-response relationships is reflected by the data in Table 1. At $24 \mathrm{~h}$ of exposure, nuclear receptor activation occurs at lower cyproconazole concentrations (reflected by a lower $\mathrm{BMC}_{50}$ ) than liver triglyceride accumulation followed by mitochondrial disruption. The same is true for $72 \mathrm{~h}$ of exposure where liver triglyceride accumulation again occurs at lower cyproconazole concentrations than mitochondrial disruption. However, the key event fatty liver cells can also be detected at lower concentrations than mitochondrial disruption although it succeeds mitochondrial disruption according to the AOP. This does not necessarily reflect an inconsistency in the expected dose-response relationship but might be due to differences in sensitivity or variability of the employed in vitro assays. For instance data suggest that liver triyglyceride accumulation analysis via GC-FID seems to be more sensitive than AdipoRed assay as BMC $_{50}$ values for GC-FID are lower at both time points. Temporal concordance implying an occurrence of upstream key events at earlier time points than downstream key events is also reflected by the data. In general 
the $\mathrm{BMC}_{50}$ values for GC-FID are lower at $72 \mathrm{~h}$ than at $24 \mathrm{~h}$ which indicates that liver triglyceride accumulation is much more pronounced after $72 \mathrm{~h}$ exposure than after $24 \mathrm{~h}$ exposure and thus is a key event that occurs later in time than earlier key events like the nuclear receptor activation. The same is true for mitochondrial disruption where the $\mathrm{BMC}_{50}$ values are also lower after $72 \mathrm{~h}$ than after $24 \mathrm{~h}$ indicating a higher incidence at later time points.

\section{Discussion}

Using the example of the AOP on liver steatosis, the data presented in this study illustrate how a battery of in vitro tests can be used to quantitatively assess key events in an AOP and thereby to obtain a comprehensive description of the biochemical changes induced by test compounds. Clearly, no single in vitro assay could cover a complex AOP like the one for liver steatosis, which involves receptor activation, transcriptional changes and alterations in cellular intermediary metabolism. Thus, a combination of several in vitro test methods in the form of a test battery is proposed as a strategy to evaluate an AOP from its molecular initiating event(s) to the cellular consequences of toxicant exposure. Previous AOP-driven steatosis screening approaches in HepaRG cells focused on later key events, but not the early molecular initiating events, has been recently put forward by Angrish et al. ${ }^{14}$ and Tolosa et al. ${ }^{15}$. The present work substantially goes beyond this previous approach now integrates data on a broader base, ranging from nuclear receptor activation to lipid accumulation, and especially by detailing the different molecular initiating events. Molecular initiating events, as well the plethora of details on thereof-dependent mRNA and protein expression alterations, have not been integrated in a comparable testing battery in the aforementioned previous publications.

Luciferase reporter-based screening of nuclear receptor activation clearly showed PXR activation by cyproconazole, a finding corroborated by induction of the model PXR target gene CYP3A4 at the mRNA and protein levels. These data do not fully reflect the results from studies in rodents, where the hepatic effects of cyproconazole are believed to be mediated mainly via CAR ${ }^{25,26,28}$. In addition to the prevailing role of CAR-dependent mechanisms, Tamura et al. ${ }^{27}$ discussed a possible involvement of PXR in cyproconazole hepatotoxicity also in mice. Induction of a variety of CAR and PXR target genes by cyproconazole in vivo has recently described by Heise et al. ${ }^{24}$. In a number of studies, it was shown that cyproconazole increases liver weight, induces hepatocyte hypertrophy and leads to lipid droplet accumulation in rodent hepatocytes in vivo ${ }^{24-26}$. The present data obtained with human HepaRG hepatoma cells convincingly show that the compound also can induce steatosis in human cells.

In the absence of evidence of CAR activation in non-rodent cell systems, it is tempting to speculate that PXR activation most likely is the main underlying mechanism by which cyproconazole induces steatosis in human cells. This situation contrasts what has been observed for mice as there was no indication of pronounced fatty acid droplet accumulation in mouse hepatocytes humanized for CAR and PXR ${ }^{25}$, thereby suggesting that CAR has a more prominent role in liver steatosis in rodents. Inter- 
species differences with regard to the ability of xenobiotics to activate CAR have been previously reported for other compounds, for example in case of the mouse-specific model CAR agonist TCPOBOP and its human counterpart CITCO ${ }^{48-50}$. Recently published data on CAR activation by other triazole fungicides confirm the functionality of the reporter assay ${ }^{51}$, thereby demonstrating the potent murine CAR agonist cyproconazole does not activate human CAR.

The present AOP 60 ("NR112 (Pregnane X Receptor, PXR) activation leading to hepatic steatosis") at www.aopwiki.org and the proposed AOP network by Mellor et al. ${ }^{12}$ depict PXR activation as a molecular initiating event followed by the key event CD36 upregulation. This designation is in line with literature reports of PXR-dependent CD36 induction ${ }^{52,53}$ and associated with an increase in cellular fatty acid influx from external sources according to the AOP. In contrast, the de novo fatty acid synthesis-related key events of MLXIPL, SREBF1, FASN, and SCD1 upregulation are not directly linked to PXR activation according to the AOP but are rather mediated by LXR, PPARY, FXR and CAR activation. In our analyses, no changes in gene expression were observed for the aforementioned players in de novo fatty acid synthesis, which is in line with the findings that cyproconazole does not activate the responsible receptors. However, also for $C D 36$ no changes in gene expression were observed. This result contradicts the existing AOP, as cyproconazole was found to be a PXR agonist. These data suggest that at the level of key events, the AOP in its present state does not fully reflect the biological processes that link nuclear receptor activation to increased cellular fatty acid contents via transcriptional changes at the mRNA level.

Activation of LXR may be capable of triggering the key event genes FASN, SCD and SREBF1 of the AOP in HepaRG cells. This situation might indicate that the present version of the AOP is centered around LXR activation, whereas signaling pathways through other nuclear receptors, which also induce steatotic processes, are not yet fully reflected. While a detailed time-resolved analysis of all molecular alterations caused by cyproconazole is outside the scope of the present study, further work, for example using specific PXR ligands, could help to close remaining gaps of the AOP network for hepatic steatosis and to include critical target genes of PXR and/or other nuclear receptors relevant for steatosis.

Another possibility for why the induction of target genes at the key event level was not observed in our analyses might be that the rate of transcriptional activation is not suitable for detecting alterations with mRNA isolation 24 hours after the start of incubation with cyproconazole. This explanation is unlikely, however, since induction of PXR target genes is generally evident in HepaRG cells $24 \mathrm{~h}$ after exposure to PXR agonists ${ }^{19}$. Moreover, known PXR target genes such as CYP3A4 were markedly induced in the present analysis. Finally, this assessment was consistent with the profile resulting from our proteomicsbased evaluation of cyproconazole exposure in HepaRG cells.

After $72 \mathrm{~h}$, later key events like triglyceride accumulation and mitochondrial disruption are clearly induced, however no changes in the abundance of proteins encoded by the target genes postulated in 
the AOP were evident except for significant reductions in ACOX1 and FASN. ACOX1 is a rate-limiting enzyme in peroxisomal fatty acid oxidation and its deletion causes microvesicular steatosis, which can progress to steatohepatitis and hepatocellular carcinoma ${ }^{54,55}$. The decrease in protein abundance of ACOX1 is in agreement with the AOP, although no PPAR a antagonistic binding, the underlying molecular initiating event, was found for cyproconazole. In contrast, FASN is an important enzyme for de novo fatty acid synthesis and it is upregulated in patients with hepatic steatosis in the absence of hepatic inflammation ${ }^{56}$. Thus, in the AOP, it is proposed to be activated by LXR, PPARY, FXR or CAR and the reduction of FASN at the protein level observed in our study is not in line with the AOP.

In the future, in vitro determination of a limited number of molecular changes induced by a test compound might be used for predicting the steatotic potential of chemicals without the need to conduct costly and ethically controversial studies in vivo. This future approach, however, will require more complete AOPs and AOP networks containing molecular mechanisms not currently (or not sufficiently) represented. Given discrepancies between observed mRNA induction and the mRNA induction pattern postulated in the steatosis AOP, the in vitro test battery developed in this work was able to recapitulate most key events of the AOP, including the molecular initiating event of nuclear receptor activation, mitochondrial disruption, lipid accumulation, and the occurrence of fatty liver cells. Furthermore, concordance in dose-response relationship as well as temporal association could be demonstrated and is in line with central AOP principles. Thus, while existing AOPs such as that for steatosis are expected to require ongoing improvements whenever more detailed mechanistic information becomes available, they nonetheless provide a potentially useful framework for guiding toxicological studies in vitro. Further research involving case studies such as the present work are anticipated to, on one hand, help confirm aspects of an AOP network, and on the other hand to critically evaluate and identify weaknesses. As elucidated in the present study, the current AOP on liver steatosis only sparsely reflects the mechanistic link between nuclear receptor activation and gene expression changes leading to hepatic steatosis. In principle, discrepancies between observed nuclear receptor activation and induction of gene expression might results from differences in cellular metabolism of the test compound, due to the fact that HepaRG cells possess higher activities of drug-metabolizing enzymes than HepG2 or HEK-293 cells. Gene expression profiles obtained in HepaRG cells show induction of CYP enzymes indicative of a nuclear receptor activation profile in this cell line comparable to the profile recorded by reporter gene assays in the other, metabolically less competent cell lines. These data strengthen the assumption that PXR activation might indeed be an important cellular factor mediating the response to cyproconazole in human liver cells. Nonetheless, activation of further steatosis-relevant nuclear receptors in HepaRG cells by metabolites not formed in HepG2 or HEK-293, and therefore not reflected in the reporter gene assay data, cannot be fully ruled out. However, the relevance of the latter scenario might be limited due to the fact that in general many metabolites, especially conjugates from phase II reactions, rarely exhibit pronounced pharmacological properties. Irrespective of the above the 
observed mRNA expression profile is not well in agreement with the postulated AOP for steatosis, thereby revealing the need for further research aimed to establish an improved AOP network with increased physiological and toxicological relevance.

Individual substances, especially from certain chemical groups such as fungicidal active compounds of the triazole class, are often quite well-characterized with respect to their toxicological profile due to the legal requirements for the registration and authorization ${ }^{57}$. Mixture toxicity is a field toxicologists have become increasingly aware of during the past few years, where much less work has been performed as compared to the analysis of individual compounds. Due to the complex nature of real-life exposure of consumers to multiple chemical entities, a testing of all these combinations in classic in vivo animal experiments, as prescribed for many endpoints in the current legislations, will not be feasible. Instead, in vitro techniques, especially combinations of different tools addressing individual aspects of a certain adverse outcome, might be increasingly used in the future. By doing so, a comprehensive description of the molecular toxicological profile of a substance can be obtained and this information can be used for predicting possible mixture effects based on similar or dissimilar molecular modes of action. In order to fulfill the latter task a detailed analysis of molecular initiating events, as done in the present work, is mandatory to determine the molecular mode of action, whereas the strength of in vitro toolboxes focused on the more apical endpoints as put forward by Tolosa et al. ${ }^{15}$ and Angrish et al. ${ }^{14}$ lies in the determination of the steatotic potential of compounds rather than in the identification of molecular mechanisms of action. By gearing at Vinken's $\mathrm{AOP}^{4}$ and by focusing on early key events important for the mode of action characterization for future use of the in vitro toolbox in mechanism-based mixture testing, less weight was put on more apical parts of the AOP, which play a major role in the apical key event-based approach by Angrish and co-workers ${ }^{13}$ 14. However, the AOP concept by Vinken ${ }^{4}$ characterizes those later key events as a consequence of mRNA and protein expression, regulated by the diverse nuclear receptors activated by steatotic compounds (see also Figure 1). Thus, even not directly measured, information on these apical key events can be extracted from our data. Nonetheless, future integration of additional apical endpoints suggested by Angrish et al. ${ }^{13}$ and Angrish et al. ${ }^{14}$ might further increase the values of the system. Testing of multiple mixtures in vitro in a test battery such as ours might constitute a feasible approach for mixture testing of chemical compounds.

\section{Funding Information}

The research leading to these results received funding from the European Union's Horizon 2020 research and innovation programme under Grant Agreement 633172 (European Test and Risk Assessment Strategies for Mixtures). This publication reflects only the author's views, and the Community is not liable for any use made of the information contained therein. 


\title{
Acknowledgments
}

We would like to thank Regina Al-Hamwi and Beatrice Rosskopp for their excellent technical support.

\section{Supporting information}

The supporting information provides as supplement Figure S1 as well as Table S1 to Table S5:

Figure S1: Cytotoxicity of cyproconazole in HepaRG, HepG2 and HEK-293 cells

Table S1: $\quad$ Plasmids, cell lines and positive controls used for the different reporter gene assays

Table S2: $\quad$ List of selected genes linked to liver steatosis, nuclear receptor activation and hepatotoxicity

Table S3: Quantotypic peptides used to compare protein level changes in cyproconazole-exposed HepaRG cells relative to untreated controls

Table S4: Results for gene expression analysis of genes linked to liver steatosis, nuclear receptor activation and hepatotoxicity

Table S5: Results for protein abundance changes in cyproconazole-exposed HepaRG cells

\begin{abstract}
Abbreviations
AIC - Akaike information criterion; AHR - aryl hydrocarbon receptor; AOP - adverse outcome pathway(s); BMC - benchmark concentration; BMCL - lower bound of the BMC confidence interval; BMCU - upper bound of the BMC confidence interval; BMR - benchmark response; CAR - constitutive androstane receptor; DBD - DNA-binding domain; FXR - farnesoid X receptor; GC-FID - gas chromatography with flame-ionization detection; GR - glucocorticoid receptor; LBD - ligand-binding domain; LXR - liver X receptor; PPAR - peroxisome proliferator-activated receptor; OCR - oxygen consumption rate; PXR - pregnane X receptor; RAR - retinoic acid receptor; PRM - Parallel Reaction Monitoring; RXR - retinoid X receptor; VDR - vitamin D receptor
\end{abstract}




\section{References}

(1) Ankley, G. T., Bennett, R. S., Erickson, R. J., Hoff, D. J., Hornung, M. W., Johnson, R. D., Mount, D. R., Nichols, J. W., Russom, C. L., Schmieder, P. K., Serrrano, J. A., Tietge, J. E., and Villeneuve, D. L. (2010) Adverse outcome pathways: a conceptual framework to support ecotoxicology research and risk assessment. Environmental toxicology and chemistry / SETAC, 29, 730-741.

(2) Edwards, S. W., Tan, Y. M., Villeneuve, D. L., Meek, M. E., and McQueen, C. A. (2016) Adverse Outcome Pathways-Organizing Toxicological Information to Improve Decision Making. The Journal of pharmacology and experimental therapeutics, 356, 170-181.

(3) Villeneuve, D. L., Crump, D., Garcia-Reyero, N., Hecker, M., Hutchinson, T. H., LaLone, C. A., Landesmann, B., Lettieri, T., Munn, S., Nepelska, M., Ottinger, M. A., Vergauwen, L., and Whelan, M. (2014) Adverse outcome pathway (AOP) development I: strategies and principles. Toxicological sciences : an official journal of the Society of Toxicology, 142, 312-320.

(4) Vinken, M. (2015) Adverse Outcome Pathways and Drug-Induced Liver Injury Testing. Chem Res Toxicol, 28, 1391-1397.

(5) Reddy, J. K., and Rao, M. S. (2006) Lipid metabolism and liver inflammation. II. Fatty liver disease and fatty acid oxidation. American journal of physiology. Gastrointestinal and liver physiology, 290, G852-858.

(6) Perumpail, B. J., Khan, M. A., Yoo, E. R., Cholankeril, G., Kim, D., and Ahmed, A. (2017) Clinical epidemiology and disease burden of nonalcoholic fatty liver disease. World Journal of Gastroenterology, 23, 8263-8276.

(7) Vilgrain, V., Ronot, M., Abdel-Rehim, M., Zappa, M., d'Assignies, G., Bruno, O., and Vullierme, M. P. (2013) Hepatic steatosis: a major trap in liver imaging. Diagn Interv Imaging, 94, 713-727.

(8) Donato, M. T., Tolosa, L., Jimenez, N., Castell, J. V., and Gomez-Lechon, M. J. (2012) Highcontent imaging technology for the evaluation of drug-induced steatosis using a multiparametric cell-based assay. J Biomol Screen, 17, 394-400.

(9) Begriche, K., Massart, J., Robin, M. A., Borgne-Sanchez, A., and Fromenty, B. (2011) Druginduced toxicity on mitochondria and lipid metabolism: mechanistic diversity and deleterious consequences for the liver. $J$ Hepatol, 54, 773-794.

(10) Hong, C., and Tontonoz, P. (2014) Liver X receptors in lipid metabolism: opportunities for drug discovery. Nat Rev Drug Discovery, 13, 433-444.

(11) Ulven, S. M., Dalen, K. T., Gustafsson, J. A., and Nebb, H. I. (2005) LXR is crucial in lipid metabolism. Prostaglandins, Leukotrienes Essent. Fatty Acids, 73, 59-63.

(12) Mellor, C. L., Steinmetz, F. P., and Cronin, M. T. (2016) The identification of nuclear receptors associated with hepatic steatosis to develop and extend adverse outcome pathways. Crit Rev Toxicol, 46, 138-152. 
(13) Angrish, M. M., Kaiser, J. P., McQueen, C. A., and Chorley, B. N. (2016) Tipping the balance: Hepatotoxicity and the 4 apical key events of hepatic steatosis. Toxicological Sciences, 150 , 261-268.

(14) Angrish, M. M., McQueen, C. A., Cohen-Hubal, E., Bruno, M., Ge, Y., and Chorley, B. N. (2017) Editor's Highlight: Mechanistic Toxicity Tests Based on an Adverse Outcome Pathway Network for Hepatic Steatosis. Toxicological Sciences, 159, 159-169.

(15) Tolosa, L., Gómez-Lechón, M. J., Jiménez, N., Hervás, D., Jover, R., and Donato, M. T. (2016) Advantageous use of HepaRG cells for the screening and mechanistic study of drug-induced steatosis. Toxicology and applied pharmacology, 302, 1-9.

(16) Aninat, C., Piton, A., Glaise, D., Le Charpentier, T., Langouet, S., Morel, F., Guguen-Guillouzo, C., and Guillouzo, A. (2006) Expression of cytochromes P450, conjugating enzymes and nuclear receptors in human hepatoma HepaRG cells. Drug metabolism and disposition: the biological fate of chemicals, 34, 75-83.

(17) Antherieu, S., Chesne, C., Li, R., Camus, S., Lahoz, A., Picazo, L., Turpeinen, M., Tolonen, A., Uusitalo, J., Guguen-Guillouzo, C., and Guillouzo, A. (2010) Stable expression, activity, and inducibility of cytochromes P450 in differentiated HepaRG cells. Drug metabolism and disposition: the biological fate of chemicals, 38, 516-525.

(18) Guillouzo, A., Corlu, A., Aninat, C., Glaise, D., Morel, F., and Guguen-Guillouzo, C. (2007) The human hepatoma HepaRG cells: a highly differentiated model for studies of liver metabolism and toxicity of xenobiotics. Chemico-biological interactions, 168, 66-73.

(19) Kanebratt, K. P., and Andersson, T. B. (2008) HepaRG cells as an in vitro model for evaluation of cytochrome P450 induction in humans. Drug metabolism and disposition: the biological fate of chemicals, 36, 137-145.

(20) Kanebratt, K. P., and Andersson, T. B. (2008) Evaluation of HepaRG cells as an in vitro model for human drug metabolism studies. Drug metabolism and disposition: the biological fate of chemicals, 36, 1444-1452.

(21) Antherieu, S., Rogue, A., Fromenty, B., Guillouzo, A., and Robin, M. A. (2011) Induction of vesicular steatosis by amiodarone and tetracycline is associated with up-regulation of lipogenic genes in HepaRG cells. Hepatology (Baltimore, Md.), 53, 1895-1905.

(22) Tanner, N., Kubik, L., Luckert, C., Thomas, M., Hofmann, U., Zanger, U. M., Bohmert, L., Lampen, A., and Braeuning, A. (2018) Regulation of drug metabolism by the interplay of inflammatory signaling, steatosis, and xeno-sensing receptors in HepaRG cells. Drug metabolism and disposition: the biological fate of chemicals.

(23) Al-Eryani, L., Wahlang, B., Falkner, K. C., Guardiola, J. J., Clair, H. B., Prough, R. A., and Cave, M. (2015) Identification of Environmental Chemicals Associated with the Development of Toxicant-associated Fatty Liver Disease in Rodents. Toxicol. Pathol., 43, 482-497. 
(24) Heise, T., Schmidt, F., Knebel, C., Rieke, S., Haider, W., Pfeil, R., Kneuer, C., Niemann, L., and Marx-Stoelting, P. (2015) Hepatotoxic effects of (tri)azole fungicides in a broad dose range. Arch Toxicol, 89, 2105-2117.

(25) Marx-Stoelting, P., Ganzenberg, K., Knebel, C., Schmidt, F., Rieke, S., Hammer, H., Schmidt, F., Potz, O., Schwarz, M., and Braeuning, A. (2017) Hepatotoxic effects of cyproconazole and prochloraz in wild-type and hCAR/hPXR mice. Arch Toxicol, 91, 2895-2907.

(26) Peffer, R. C., Moggs, J. G., Pastoor, T., Currie, R. A., Wright, J., Milburn, G., Waechter, F., and Rusyn, I. (2007) Mouse liver effects of cyproconazole, a triazole fungicide: role of the constitutive androstane receptor. Toxicological sciences : an official journal of the Society of Toxicology, 99, 315-325.

(27) Tamura, K., Inoue, K., Takahashi, M., Matsuo, S., Irie, K., Kodama, Y., Gamo, T., Ozawa, S., and Yoshida, M. (2015) Involvement of constitutive androstane receptor in liver hypertrophy and liver tumor development induced by triazole fungicides. Food Chem Toxicol, 78, 86-95.

(28) Tamura, K., Inoue, K., Takahashi, M., Matsuo, S., Irie, K., Kodama, Y., Ozawa, S., Nishikawa, A., and Yoshida, M. (2013) Dose-response involvement of constitutive androstane receptor in mouse liver hypertrophy induced by triazole fungicides. Toxicology letters, 221, 47-56.

(29) Kanno, Y., and Inouye, Y. (2010) A consecutive three alanine residue insertion mutant of human CAR: a novel CAR ligand screening system in HepG2 cells. The Journal of toxicological sciences, 35, 515-525.

(30) Chen, T., Tompkins, L. M., Li, L., Li, H., Kim, G., Zheng, Y., and Wang, H. (2010) A single amino acid controls the functional switch of human constitutive androstane receptor (CAR) 1 to the xenobiotic-sensitive splicing variant CAR3. The Journal of pharmacology and experimental therapeutics, 332, 106-115.

(31) Kliewer, S. A., Sundseth, S. S., Jones, S. A., Brown, P. J., Wisely, G. B., Koble, C. S., Devchand, P., Wahli, W., Willson, T. M., Lenhard, J. M., and Lehmann, J. M. (1997) Fatty acids and eicosanoids regulate gene expression through direct interactions with peroxisome proliferator-activated receptors alpha and gamma. Proc Natl Acad Sci U S A, 94, 4318-4323.

(32) Luckert, C., Ehlers, A., Buhrke, T., Seidel, A., Lampen, A., and Hessel, S. (2013) Polycyclic aromatic hydrocarbons stimulate human CYP3A4 promoter activity via PXR. Toxicology letters, 222, 180-188.

(33) Schulthess, P., Loffler, A., Vetter, S., Kreft, L., Schwarz, M., Braeuning, A., and Bluthgen, N. (2015) Signal integration by the CYP1A1 promoter--a quantitative study. Nucleic Acids Research, 43, 5318-5330.

(34) Zukunft, J., Lang, T., Richter, T., Hirsch-Ernst, K. I., Nussler, A. K., Klein, K., Schwab, M., Eichelbaum, M., and Zanger, U. M. (2005) A natural CYP2B6 TATA box polymorphism (-82T--> 
C) leading to enhanced transcription and relocation of the transcriptional start site. Molecular pharmacology, 67, 1772-1782.

(35) Quack, M., Szafranski, K., Rouvinen, J., and Carlberg, C. (1998) The role of the T-box for the function of the vitamin $\mathrm{D}$ receptor on different types of response elements. Nucleic Acids Research, 26, 5372-5378.

(36) Forman, B. M., Umesono, K., Chen, J., and Evans, R. M. (1995) Unique response pathways are established by allosteric interactions among nuclear hormone receptors. Cell, 81, 541-550.

(37) Livak, K. J., and Schmittgen, T. D. (2001) Analysis of relative gene expression data using realtime quantitative PCR and the 2(-Delta Delta C(T)) Method. Methods, 25, 402-408.

(38) Peterson, A. C., Russell, J. D., Bailey, D. J., Westphall, M. S., and Coon, J. J. (2012) Parallel reaction monitoring for high resolution and high mass accuracy quantitative, targeted proteomics. Mol Cell Proteomics, 11, 1475-1488.

(39) MacLean, B., Tomazela, D. M., Shulman, N., Chambers, M., Finney, G. L., Frewen, B., Kern, R., Tabb, D. L., Liebler, D. C., and MacCoss, M. J. (2010) Skyline: an open source document editor for creating and analyzing targeted proteomics experiments. Bioinformatics (Oxford, England), 26, 966-968.

(40) Bruderer, R., Bernhardt, O. M., Gandhi, T., and Reiter, L. (2016) High-precision iRT prediction in the targeted analysis of data-independent acquisition and its impact on identification and quantitation. Proteomics, 16, 2246-2256.

(41) Hutchins, P. M., Barkley, R. M., and Murphy, R. C. (2008) Separation of cellular nonpolar neutral lipids by normal-phase chromatography and analysis by electrospray ionization mass spectrometry. J Lipid Res, 49, 804-813.

(42) Smolina, N., Bruton, J., Kostareva, A., and Sejersen, T. (2017) Assaying Mitochondrial Respiration as an Indicator of Cellular Metabolism and Fitness, In Cell Viability Assays: Methods and Protocols (Gilbert, D. F., and Friedrich, O., Eds.) pp 79-87, Springer New York, New York, NY.

(43) Salabei, J. K., Gibb, A. A., and Hill, B. G. (2014) Comprehensive measurement of respiratory activity in permeabilized cells using extracellular flux analysis. Nature Protocols, 9, 421-438.

(44) Amacher, D. E., and Martin, B.-A. (1997) Tetracycline-Induced Steatosis in Primary Canine Hepatocyte Cultures. Fundam. Appl. Toxicol., 40, 256-263.

(45) McMillian, M. K., Grant, E. R., Zhong, Z., Parker, J. B., Li, L., Zivin, R. A., Burczynski, M. E., and Johnson, M. D. (2001) Nile Red binding to HepG2 cells: an improved assay for in vitro studies of hepatosteatosis. In Vitro Mol Toxicol, 14, 177-190.

(46) Meek, M. E., Boobis, A., Cote, I., Dellarco, V., Fotakis, G., Munn, S., Seed, J., and Vickers, C. (2014) New developments in the evolution and application of the WHO/IPCS framework on mode of action/species concordance analysis. Journal of applied toxicology : JAT, 34, 1-18. 
(47) Villeneuve, D. L., Crump, D., Garcia-Reyero, N., Hecker, M., Hutchinson, T. H., LaLone, C. A., Landesmann, B., Lettieri, T., Munn, S., Nepelska, M., Ottinger, M. A., Vergauwen, L., and Whelan, M. (2014) Adverse outcome pathway development II: best practices. Toxicological sciences : an official journal of the Society of Toxicology, 142, 321-330.

(48) Maglich, J. M., Parks, D. J., Moore, L. B., Collins, J. L., Goodwin, B., Billin, A. N., Stoltz, C. A., Kliewer, S. A., Lambert, M. H., Willson, T. M., and Moore, J. T. (2003) Identification of a novel human constitutive androstane receptor (CAR) agonist and its use in the identification of CAR target genes. The Journal of biological chemistry, 278, 17277-17283.

(49) Moore, L. B., Parks, D. J., Jones, S. A., Bledsoe, R. K., Consler, T. G., Stimmel, J. B., Goodwin, B., Liddle, C., Blanchard, S. G., Willson, T. M., Collins, J. L., and Kliewer, S. A. (2000) Orphan nuclear receptors constitutive androstane receptor and pregnane $X$ receptor share xenobiotic and steroid ligands. The Journal of biological chemistry, 275, 15122-15127.

(50) Scheer, N., Ross, J., Rode, A., Zevnik, B., Niehaves, S., Faust, N., and Wolf, C. R. (2008) A novel panel of mouse models to evaluate the role of human pregnane $X$ receptor and constitutive androstane receptor in drug response. J Clin Invest, 118, 3228-3239.

(51) Knebel, C., Neeb, J., Zahn, E., Schmidt, F., Carazo, A., Holas, O., Pavek, P., Puschel, G. P., Zanger, U. M., Sussmuth, R., Lampen, A., Marx-Stoelting, P., and Braeuning, A. (2018) Unexpected effects of propiconazole, tebuconazole and their mixture on the receptors CAR and PXR in human liver cells. Toxicological sciences : an official journal of the Society of Toxicology.

(52) Zhou, J., Febbraio, M., Wada, T., Zhai, Y., Kuruba, R., He, J., Lee, J. H., Khadem, S., Ren, S., Li, S., Silverstein, R. L., and Xie, W. (2008) Hepatic fatty acid transporter Cd36 is a common target of LXR, PXR, and PPARgamma in promoting steatosis. Gastroenterology, 134, 556-567.

(53) Zhou, J., Zhai, Y., Mu, Y., Gong, H., Uppal, H., Toma, D., Ren, S., Evans, R. M., and Xie, W. (2006) A novel pregnane $X$ receptor-mediated and sterol regulatory element-binding proteinindependent lipogenic pathway. The Journal of biological chemistry, 281, 15013-15020.

(54) Fan, C. Y., Pan, J., Chu, R., Lee, D., Kluckman, K. D., Usuda, N., Singh, I., Yeldandi, A. V., Rao, M. S., Maeda, N., and Reddy, J. K. (1996) Hepatocellular and hepatic peroxisomal alterations in mice with a disrupted peroxisomal fatty acyl-coenzyme A oxidase gene. The Journal of biological chemistry, 271, 24698-24710.

(55) Fan, C. Y., Pan, J., Usuda, N., Yeldandi, A. V., Rao, M. S., and Reddy, J. K. (1998) Steatohepatitis, spontaneous peroxisome proliferation and liver tumors in mice lacking peroxisomal fatty acyl-CoA oxidase. Implications for peroxisome proliferator-activated receptor alpha natural ligand metabolism. The Journal of biological chemistry, 273, 15639-15645. 
(56) Dorn, C., Riener, M. O., Kirovski, G., Saugspier, M., Steib, K., Weiss, T. S., Gabele, E., Kristiansen, G., Hartmann, A., and Hellerbrand, C. (2010) Expression of fatty acid synthase in nonalcoholic fatty liver disease. Int J Clin Exp Pathol, 3, 505-514.

(57) EC. (2009) Regulation (EC) No 1107/2009 of the European Parliament and of the Council of 21 October 2009 concerning the placing of plant protection products on the market and repealing Council Directives 79/117/EEC and 91/414/EEC. Official Journal of the European Union, L 309, $1-50$. 
Tables

Table 1: $\mathrm{BMC}_{50}$ values for in vitro assays after $24 \mathrm{~h}$ or $72 \mathrm{~h}$ of cyproconazole exposure ${ }^{a}$

\begin{tabular}{|c|c|c|c|c|c|}
\hline $\begin{array}{l}\text { Exposure } \\
\text { time }\end{array}$ & Key event & In vitro assay & $\begin{array}{c}\mathrm{BMC}_{50} \\
{[\mu \mathrm{M}]}\end{array}$ & $\begin{array}{c}\mathrm{BMCL}_{50} \\
{[\mu \mathrm{M}]}\end{array}$ & $\begin{array}{c}\mathrm{BMCU}_{50} \\
{[\mu \mathrm{M}]}\end{array}$ \\
\hline \multirow{18}{*}{$24 \mathrm{~h}$} & Nuclear receptor activation & PXR-CYP2B6 & 1.5 & 0.4 & 3.7 \\
\hline & Nuclear receptor activation & PXR & 17.7 & 8.7 & 28.8 \\
\hline & Nuclear receptor activation & RAR & 23.3 & 16.3 & 31.0 \\
\hline & Liver triglyceride accumulation & GC-FID (C54) & 30.3 & 6.3 & 79.6 \\
\hline & Liver triglyceride accumulation & GC-FID (C52) & 49.2 & 12.1 & 114.0 \\
\hline & Liver triglyceride accumulation & GC-FID (C56) & 61.8 & 16.5 & 133.0 \\
\hline & Liver triglyceride accumulation & GC-FID (C46) & 79.1 & 30.7 & 141.0 \\
\hline & Liver triglyceride accumulation & GC-FID (C50) & 88.5 & 34.3 & 157.0 \\
\hline & Liver triglyceride accumulation & GC-FID (C48) & 93.4 & 40.9 & 152.0 \\
\hline & Mitochondrial disruption & Non-mitochondrial respiration & 174.6 & 142.0 & 187.0 \\
\hline & Liver triglyceride accumulation & GC-FID (C42) & 179.5 & 80.7 & 430.0 \\
\hline & Liver triglyceride accumulation & GC-FID (C44) & 188.1 & 107.0 & 367.0 \\
\hline & Mitochondrial disruption & ATP production & 191.8 & 129.0 & 289.0 \\
\hline & Mitochondrial disruption & Spare respiratory capacity & 196.4 & 123.0 & 360.0 \\
\hline & Mitochondrial disruption & Maximal respiration & 201.7 & 131.0 & 372.0 \\
\hline & Mitochondrial disruption & Basal respiration & 213.3 & 151.0 & 414.0 \\
\hline & Mitochondrial disruption & Proton leak & 247.2 & 173.0 & 2300.0 \\
\hline & Liver triglyceride accumulation & AdipoRed & 334.4 & 257.0 & 588.0 \\
\hline \multirow{16}{*}{$72 \mathrm{~h}$} & Liver triglyceride accumulation & GC-FID (C54) & 7.5 & 3.2 & 15.1 \\
\hline & Liver triglyceride accumulation & GC-FID (C56) & 11.2 & 5.4 & 20.6 \\
\hline & Liver triglyceride accumulation & GC-FID (C52) & 23.6 & 10.9 & 43.7 \\
\hline & Liver triglyceride accumulation & GC-FID (C42) & 78.2 & 58.1 & 97.3 \\
\hline & Liver triglyceride accumulation & GC-FID (C46) & 80.4 & 67.2 & 94.8 \\
\hline & Liver triglyceride accumulation & GC-FID (C48) & 80.4 & 67.2 & 94.8 \\
\hline & Liver triglyceride accumulation & GC-FID (C50) & 92.0 & 73.0 & 109.0 \\
\hline & Liver triglyceride accumulation & GC-FID (C44) & 96.1 & 77.7 & 123.0 \\
\hline & Mitochondrial disruption & Basal respiration & 119.3 & 102.0 & 173.0 \\
\hline & Fatty liver cells & High content cell imaging & 121.9 & 46.2 & 302.0 \\
\hline & Mitochondrial disruption & Spare respiratory capacity & 132.4 & 107.0 & 158.0 \\
\hline & Liver triglyceride accumulation & AdipoRed & 135.9 & 122.0 & 152.0 \\
\hline & Mitochondrial disruption & Maximal respiration & 138.6 & 112.0 & 163.0 \\
\hline & Mitochondrial disruption & Non-mitochondrial respiration & 142.0 & 104.0 & 161.0 \\
\hline & Mitochondrial disruption & Proton leak & 152.8 & 98.2 & 199.0 \\
\hline & Mitochondrial disruption & ATP production & 163.1 & 140.0 & 182.0 \\
\hline
\end{tabular}


${ }^{a}$ Dose-response modeling and benchmark dose (BMC) analysis were performed using the software package PROAST. The BMC and the respective two-sided $90 \%$ BMC confidence interval given by BMCL (lower bound of the BMC confidence interval) and BMCU (upper bound of the BMC confidence interval) were calculated for a benchmark response of $50 \%\left(\mathrm{BMR}_{50}\right)$. Data were sorted for $\mathrm{BMC}_{50}$. For high content cell imaging data after $24 \mathrm{~h}$ exposure no $\mathrm{BMC}_{50}$ could be calculated due to the maximal response lying below a $50 \%$ change in response relative to the background.

Figures and Figure Legends

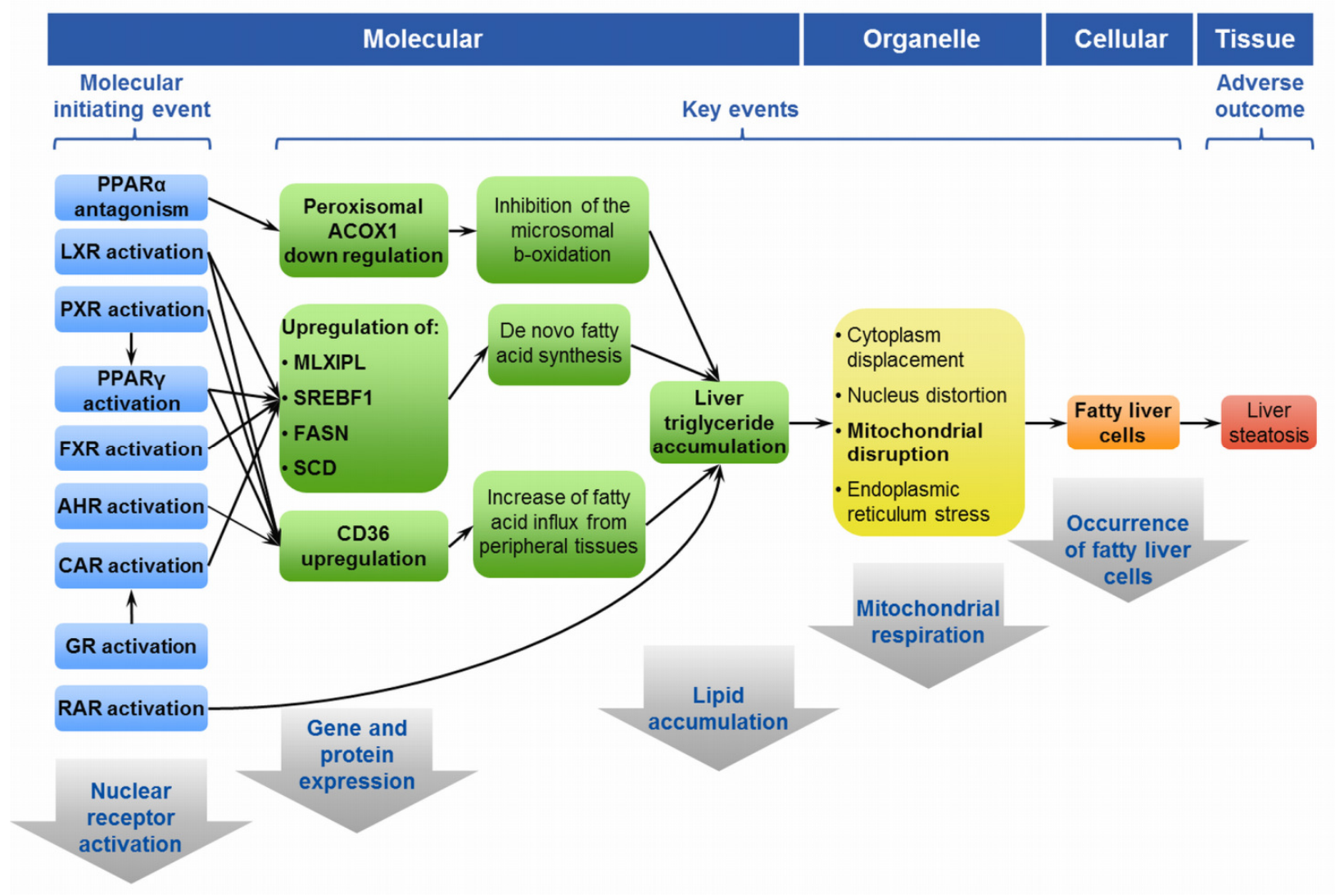

Figure 1: AOP network for liver steatosis and in vitro endpoints to access AOP. The figure was compiled on the basis of previously published literature modified after ${ }^{4,12}$. Key events analyzed in the present study are marked in bold letters. 
<smiles>CC(C1CC1)C(O)(Cn1cncn1)c1ccc(Cl)cc1</smiles>

Figure 2: Chemical structure of cyproconazole.

A

\begin{tabular}{lc}
\hline Assay & Activation \\
\hline AHR & - \\
CAR & - \\
CAR-CYP2B6 & - \\
FXR & - \\
GR & - \\
LXRa & - \\
PPAR $\alpha$ & - \\
PPARY & - \\
PPARó & - \\
PXR & + \\
PXR-CYP2B6 & + \\
RAR & + \\
RXR & - \\
VDR-CYP2B6 & - \\
\hline
\end{tabular}

B

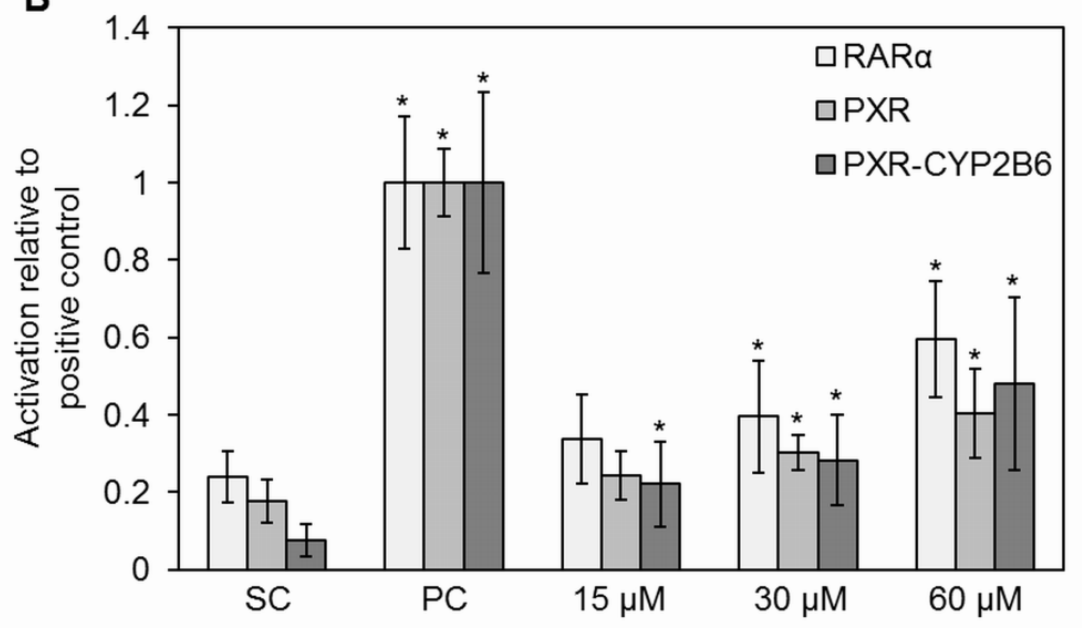

Figure 3: Nuclear receptor activation by cyproconazole. Reporter gene assays were used to analyze the activation of the ligand binding domain (LBD) of different nuclear receptors (CAR, FXR, LXRa, PPARa, PPARY, PPARס, PXR, RARa, RXRa), the receptor-mediated induction of a specific DNA response element (AHR, GR), or the human CYP2B6 promoter (CAR-/PXR-/VDR-CYP2B6). For this purpose HepG2 or HEK-293 cells (depending on the reporter gene assay) were transfected with the appropriate plasmids and exposed to indicated cyproconazole concentrations, solvent control (SC; $0.5 \% \mathrm{DMSO}$ ) or to the respective positive control (PC, listed in supplement, Table S1) for $24 \mathrm{~h}$. Relative activity referred to maximum induction by the PC (set to 1) was calculated. Data are presented as means \pm SD (* $p<0.05$ Kruskal-Wallis test against SC). (A) Summary of receptor activation (+ activation, - no activation). (B) Detailed results for PXR and RARa activation by cyproconazole. 
A PCR array screening $(200 \mu \mathrm{M}$ cyproconazole):

\begin{tabular}{lclclc}
\hline Gene & Fold change & Gene & Fold change & Gene & Fold change \\
\hline ACACA & 1.93 & CYP3A7 & 6.00 & MTTP & -1.30 \\
ACOX1 & 1.01 & CYP7A1 & -2.13 & NOS2 & -1.18 \\
ADK & 1.90 & CYP7B1 & -1.25 & NQO1 & 1.82 \\
ALDH1A1 & -1.28 & DNM1 & 1.12 & NR0B2 & -1.21 \\
ALDH2 & 1.50 & ENO1 & -1.18 & PCCA & -1.29 \\
AQP2 & N.D. & FAS & 1.06 & PDK4 & -1.70 \\
ATP8B1 & 1.80 & FASN & -2.59 & PNPLA3 & -1.50 \\
CCL5 & -1.13 & FBXO32 & 1.37 & POR & 2.02 \\
CD36 & -1.22 & G6PC & -1.97 & PPARA & 1.75 \\
CEBPD & -1.60 & G6PD & 1.31 & PPARGC1A & 2.31 \\
CES2 & 1.25 & GPD1 & -1.44 & RETN & N.D. \\
COMT & 1.20 & HAAO & -1.23 & RGCC & -2.05 \\
CYBB & 1.04 & HADHB & 1.62 & SCD & 2.14 \\
CYP1A2 & 5.00 & IL6 & -1.60 & SLCO4A1 & 1.21 \\
CYP1B1 & 4.62 & INSIG1 & 2.03 & $\underline{\text { SREBF1 }}$ & -1.38 \\
CYP2A6 & 1.09 & JUN & 1.46 & STBD1 & 1.80 \\
CYP2B6 & 6.91 & KHK & -1.28 & SULT1B1 & -3.40 \\
CYP2C19 & 1.51 & LMNA & -1.17 & SULT1C2 & 2.63 \\
CYP2C9 & -1.17 & LPL & 2.31 & SYT1 & -1.12 \\
CYP2D6 & 1.21 & LY6D & -2.31 & TFF3 & -1.95 \\
CYP2E1 & -3.50 & MAPK8 & 2.06 & TUBB2B & 1.36 \\
CYP3A4 & 14.70 & MLXIPL & -1.21 & UGT2B7 & -1.87 \\
CYP3A5 & 2.45 & MSMO1 & 1.66 & VCP & -1.24 \\
\hline
\end{tabular}

B

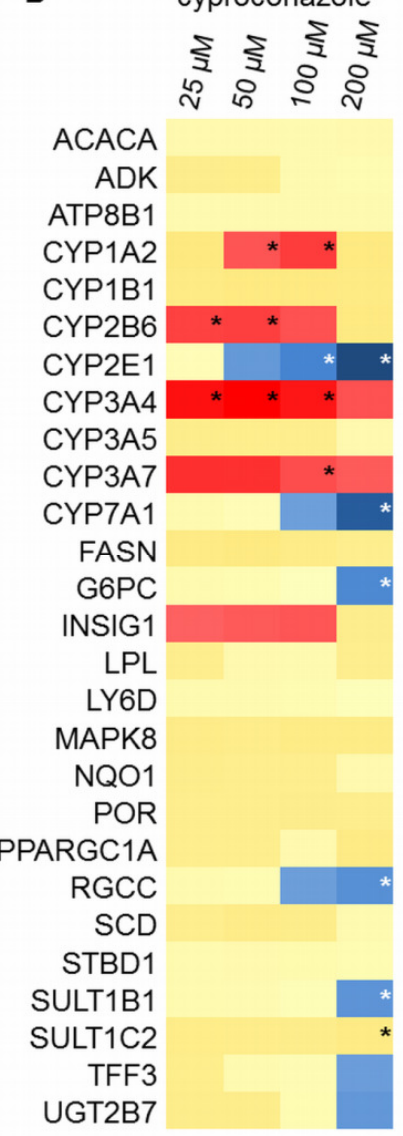

Figure 4: Gene expression analysis of genes linked to liver steatosis, nuclear receptor activation and hepatotoxicity. Differentiated HepaRG cells were exposed to $25 \mu \mathrm{M}, 50 \mu \mathrm{M}, 100 \mu \mathrm{M}$, or $200 \mu \mathrm{M}$ cyproconazole for 24 h. $0.5 \%$ DMSO served as solvent control. Total mRNA was isolated and transcribed into cDNA. (A) Using cDNA from solvent controls and $200 \mu \mathrm{M}$ cyproconazole-treated samples, a set of 69 steatosis-related target genes was analyzed by TaqMan real-time PCR array analysis. Two technical replicates were analyzed for each condition. For relative quantification of mRNA content according to the $2^{-\triangle A C t}$ method, Ct values were normalized to reference genes ACTB, GAPDH and B2M. mRNA level in treated samples is expressed as fold change in relation to solvent control (set to 1). Fold changes $\geq 2$ and $\leq-2$ are highlighted in orange and blue, respectively. Genes in the AOP are underlined. (B) Based on the PCR array screening, 27 genes deregulated with a |fold change almost equaling or higher than 2 were selected for further PCR analysis in cells treated with increasing concentrations of cyproconazole. The heat map presents the mean fold changes of three independent, biological replicates ( ${ }^{*} p<0.05$ Kruskal-Wallis test against solvent control). 


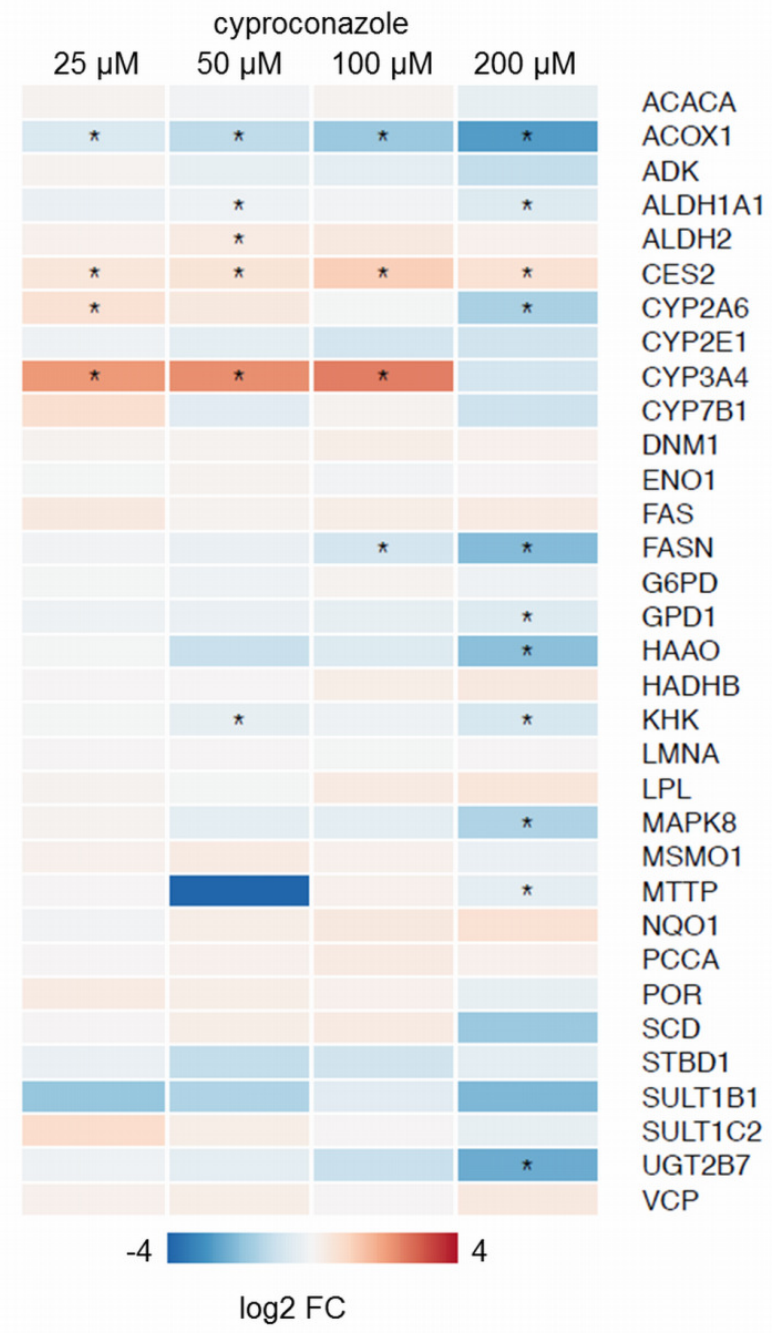

Figure 5: Protein abundance changes of cyproconazole-perturbed HepaRG cells represented as a heat map. HepaRG cells were exposed for $72 \mathrm{~h}$ to increasing concentrations of cyproconazole relative to solvent controls (0.5\% DMSO) and protein abundance changes were monitored using MS-based parallel reaction monitoring (PRM) assays. Only proteins which corresponded to the gene transcripts analyzed by TaqMan real-time PCR array analysis and which were uniquely identified by PRM are presented. Legend depicts fold change $(F C)$ on a $\log _{2}$ scale. *: significant change (increase or decrease in abundance) as determined by unpaired t-test compared to untreated control cells ( $p<$ $0.05)$. 

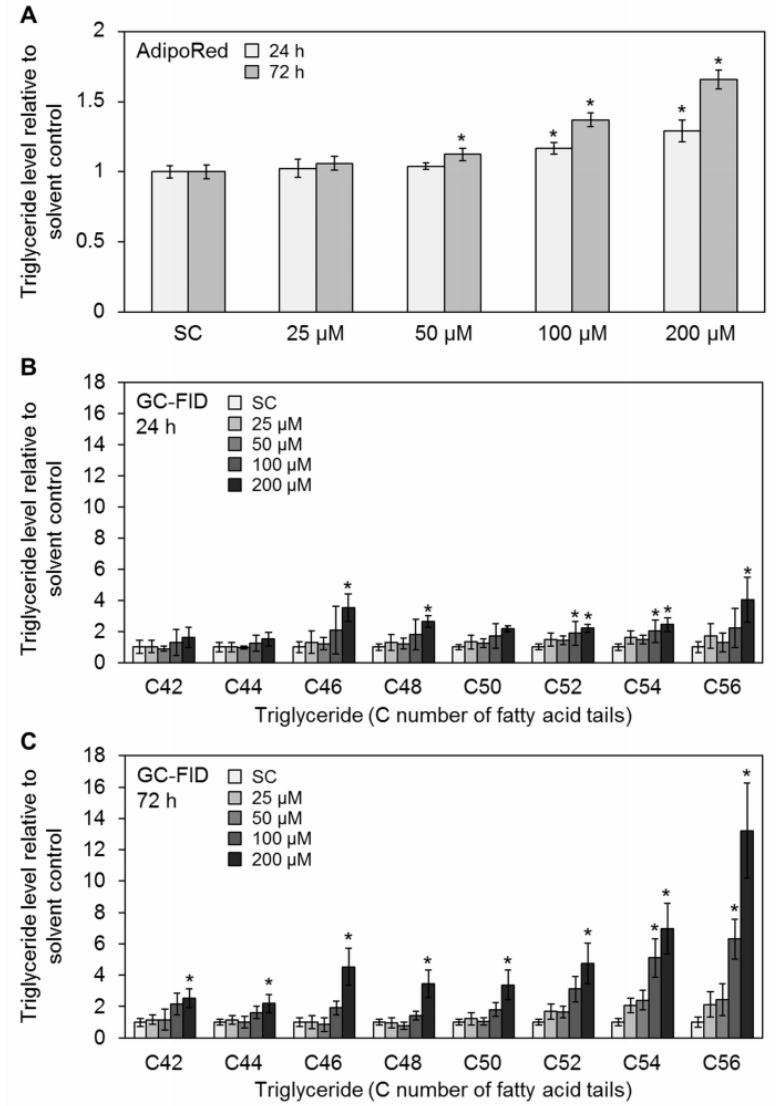

Figure 6: Analysis of triglyceride accumulation. Differentiated HepaRG cells were exposed to the indicated concentrations of cyproconazole or solvent control (SC; $0.5 \% \mathrm{DMSO}$ ). After $24 \mathrm{~h}$ or $72 \mathrm{~h}$ triglyceride accumulation was analyzed using (A) AdipoRed assay or (B,C) GC-FID. The triglyceride content was referred to the solvent control. Data are presented as means \pm SD $\left({ }^{*} p<0.05\right.$ KruskalWallis test against SC). 

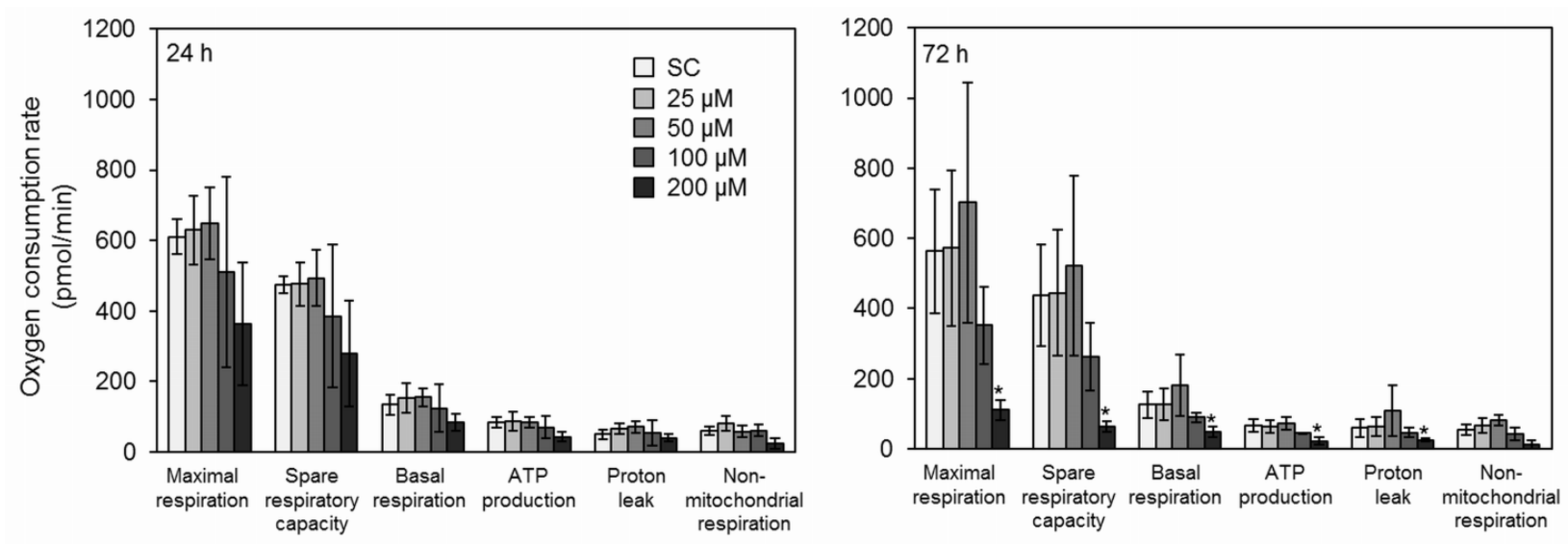

Figure 7: Mitochondrial respiration. Differentiated HepaRG cells were exposed to the indicated concentrations of cyproconazole or solvent control (SC; 0.5\%DMSO) for $24 \mathrm{~h}$ and $72 \mathrm{~h}$. Mitochondrial respiration was assessed by measuring the oxygen consumption rate using the Seahorse XF Cell Mito Stress Test. Data are presented as means \pm SD ( ${ }^{*} p<0.05$ Kruskal-Wallis test against SC). 

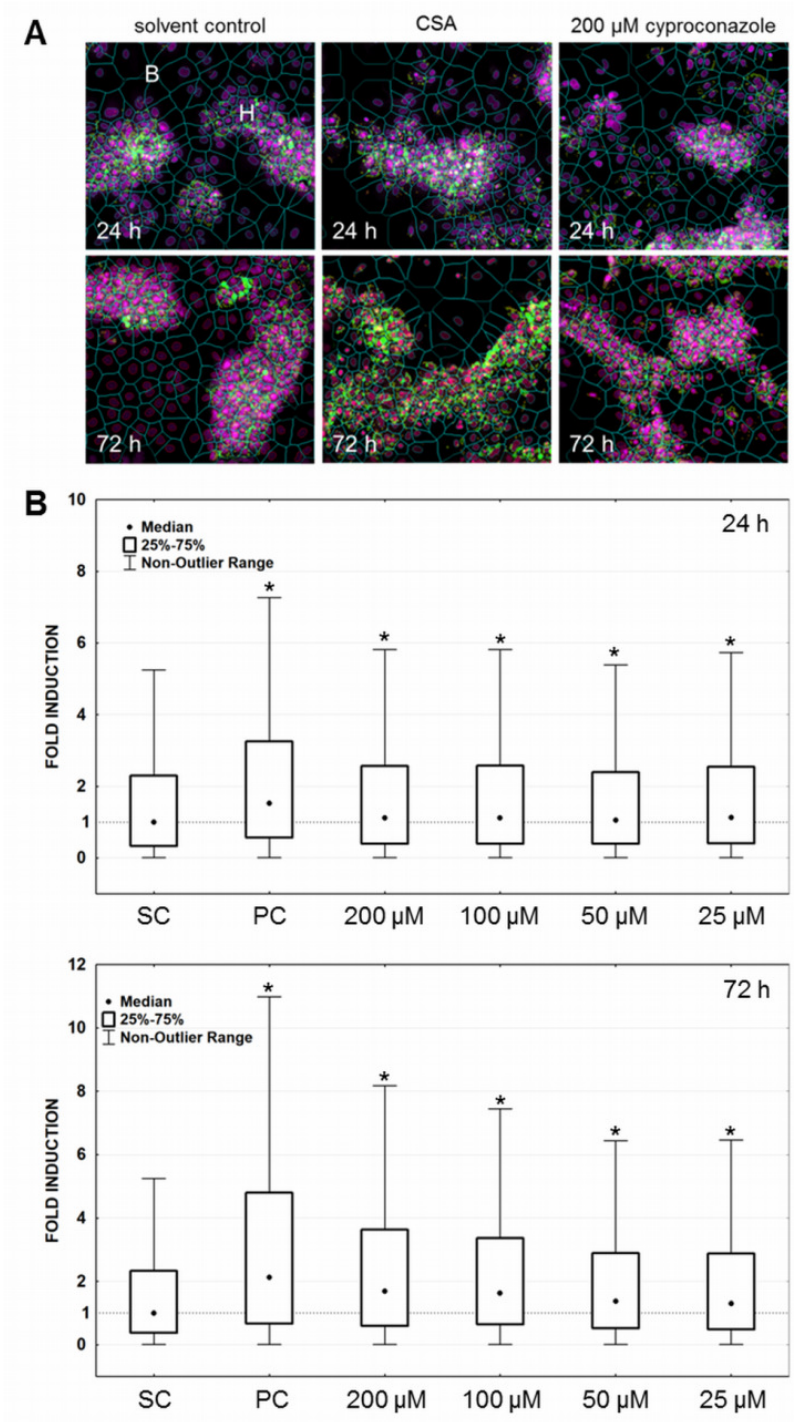

Figure 8: High content cell imaging of neutral lipid droplets. Differentiated HepaRG cells were exposed to indicated cyproconazole concentrations, $30 \mu \mathrm{M}$ cyclosporine A serving as positive control (PC), or solvent control (SC; $0.5 \%$ DMSO). After $24 \mathrm{~h}$ or $72 \mathrm{~h}$ nuclei were stained with DAPI. Neutral lipids were visualized using nile red dye and then subjected to high content cell imaging analysis. Spot total intensity was quantified in each cell, and then normalized using median MAD. Fold induction relative to solvent control was calculated. (A) Representative fluorescence images of stained cells. Fuchsia: DAPI (nuclei); green: nile red (triglycerides); $\mathrm{H}$ : hepatocyte-like cells; $\mathrm{B}$ : bile duct epithelium-like cells. (B) Dose-response diagram for relative fold induction of spot total intensities. The boxes depict the median and the $25 \%-75 \%$ range of nile red staining intensity in hepatocytes $\left({ }^{*} p<0.05\right.$ Kruskal-Wallis test against SC). 